\title{
Induction of Neuronal Vascular Endothelial Growth Factor Expression by cAMP in the Dentate Gyrus of the Hippocampus Is Required for Antidepressant-Like Behaviors
}

\author{
Jeong-Sik Lee, ${ }^{1}$ Deok-Jin Jang, ${ }^{3}$ Nuribalhae Lee, ${ }^{3}$ Hyoung-Gon Ko, ${ }^{3}$ Hyoung Kim, ${ }^{3}$ Yong-Seok Kim, ${ }^{1}$ Byungwoo Kim, ${ }^{1}$ \\ Junehee Son, ${ }^{3}$ Sung Hyun Kim, ${ }^{1}$ Heekyoung Chung, ${ }^{2}$ Mun-Yong Lee, ${ }^{5}$ Woon Ryoung Kim, ${ }^{6}$ Woong Sun, ${ }^{6}$ Min Zhuo, \\ Ted Abel, ${ }^{8}$ Bong-Kiun Kaang, ${ }^{3,4}$ and Hyeon Son ${ }^{1}$ \\ Departments of ${ }^{1}$ Biochemistry and Molecular Biology and ${ }^{2}$ Pathology, Hanyang University College of Medicine, 133-791 Seoul, Korea, Departments of \\ ${ }^{3}$ Biological Sciences and ${ }^{4}$ Brain and Cognitive Sciences, College of Natural Sciences, Seoul National University, 151-742 Seoul, Korea, ${ }^{5}$ Department of \\ Anatomy, College of Medicine, The Catholic University of Korea, 137-701 Seoul, Korea, ${ }^{6}$ Department of Anatomy, Korea University College of Medicine, \\ 136-701 Seoul, Korea, ${ }^{7}$ Department of Physiology, Faculty of Medicine, University of Toronto, Toronto, Ontario M5S 1A8, Canada, and ${ }^{8}$ Department of \\ Biology, University of Pennsylvania, Philadelphia, Pennsylvania 19104
}

The cAMP cascade and vascular endothelial growth factor (VEGF) are critical modulators of depression. Here we have tested whether the antidepressive effect of the cAMP cascade is mediated by VEGF in the adult hippocampus. We used a conditional genetic system in which the Aplysia octopamine receptor $\left(\mathrm{Ap} \mathrm{oa}_{1}\right), \mathrm{a} \mathrm{G}_{\mathrm{s}}$-coupled receptor, is transgenically expressed in the forebrain neurons of mice. Chronic activation of the heterologous $\mathrm{Ap} \mathrm{oa}_{1}$ by its natural ligand evoked antidepressant-like behaviors, accompanied by enhanced phosphorylation of cAMP response element-binding protein and transcription of VEGF in hippocampal dentate gyrus (DG) neurons. Selective knockdown of VEGF in these cells during the period of cAMP elevation inhibited the antidepressant-like behaviors. These findings reveal a molecular interaction between the CAMP cascade and VEGF expression, and the pronounced behavioral consequences of this interaction shed light on the mechanism underlying neuronal VEGF functions in antidepression.

\section{Introduction}

Although antidepressants (ADs), such as fluoxetine, are widely prescribed, their mechanism of action remains unclear. Monoaminergic signals acting mainly via G-proteins and leading to alterations of adenylyl cyclase activity and intracellular cAMP levels, are thought to underlie the pathophysiology of depression (Nestler et al., 2002; Gass and Riva, 2007). Neurotrophic factors, such as brain-derived neurotrophic factor (BDNF) and vascular endothelial growth factor (VEGF), are also believed to contribute to the effects of AD treatments (Nibuya et al., 1995; Ansorge et al., 2006; Duman and Monteggia, 2006; Warner-Schmidt and Duman, 2007, 2008; Adachi et al., 2008). AD drugs that counteract the pathophysiology of depression activate the cAMP-CREB (cAMP response element-binding protein) cascade (Nibuya et al., 1996; Thome et al., 2000; Blom et al., 2002; Tiraboschi et al., 2004; Gass and Riva, 2007) and increase neurogenesis (Malberg et

Received March 18, 2009; revised May 7, 2009; accepted May 26, 2009.

This work was supported by grants from the Brain Research Center of the 21st Century Frontier Research Program and the Korea Science and Engineering Foundation (ROI-2007-000-20222-0) awarded to H.S. by the Ministry of Science and Technology, Republic of Korea, and the National Creative Research Initiative Program (B.-K.K.) of the Korean Ministry of Science and Technology, Republic of Korea. D.-J.J., N.L., and H.-G.K. are supported by BK21 fellowships. We thank Prof. Pyeung-Hyeun Kim for the VEGF promoter and CREB expression constructs.

Correspondence should be addressed to Hyeon Son at the above address. E-mail: hyeonson@hanyang.ac.kr.

D01:10.1523/JNEUROSCI.1321-09.2009

Copyright $\odot 2009$ Society for Neuroscience $\quad 0270-6474 / 09 / 298493-13 \$ 15.00 / 0$ al., 2000; Eisch, 2002; Santarelli et al., 2003; Sairanen et al., 2005; Sahay and Hen, 2007) in the hippocampus. Genetic manipulation of levels of CREB (Chen et al., 2001; Gass and Riva, 2007; Gur et al., 2007) and BDNF (Adachi et al., 2008) in animals shows that the behavioral effects of ADs are hippocampus-dependent because selective overexpression of CREB or loss of BDNF in the DG alters depression-related behaviors such as the forced swim test (FST) (Chen et al., 2001), and responses to ADs (Adachi et al., 2008). Recently, putative CREB responsive elements (CREs) have been detected in the VEGF promoters of rodents (Impey et al., 2004; Jeon et al., 2007). However, no studies have specifically addressed the possible regulation of VEGF expression by cAMPCREB in antidepression.

We therefore tested, using an animal model, whether neuronal VEGF gene expression is controlled by the cAMP cascade, by elevating cAMP levels preferentially in the hippocampus, which is linked to depression and neurogenesis (Malberg et al., 2000; Thome et al., 2000; Eisch, 2002; Gass and Riva, 2007; Sahay and Hen, 2007). We used mice carrying Ap oa ${ }_{1}$, a $\mathrm{G}_{\mathrm{s}}$-coupled receptor, in which cAMP can be specifically elevated in CaMKII $\alpha$ expressing neurons in a time-limited manner (Isiegas et al., 2008). Ap oa transgenic mice do not display any abnormal phenotype (Isiegas et al., 2008): basal synaptic transmission and glutamatergic excitatory neurotransmission are normal, movement, 
reflexes and autonomic functions are unaffected, and intraperitoneal administration of the natural ligand octopamine does not affect perception, nociception, motor activity, or freezing behavior (Isiegas et al., 2008; Wu et al., 2008).

Since intraperitoneal injection of octopamine in $\mathrm{Ap} \mathrm{oa}$ mice rapidly elevates hippocampal cAMP levels (Isiegas et al., 2008), we hypothesized that exposure to octopamine should be sufficient to induce the CAMP-CREB-dependent AD effect. We report here that cell type-specific expression of $A p$ oa $_{1}$ in the mammalian brain can induce the formation of an effector (VEGF) and lead to behavioral changes in an animal model. By knocking down VEGF in a region restricted to the DG, and for a time limited to the period of cAMP elevation, we have shown that neuronal VEGF expression is required around the time of activation of cAMP-CREB signaling in the adult hippocampus to achieve a depression-resistant state.

\section{Materials and Methods}

Mice. All animal experiments were approved by the Institutional Animal Care and Use Committee of Hanyang University and were performed in accordance with relevant guidelines and regulations. Mice heterologous for $\mathrm{Ap} \mathrm{oa}_{1}$ and their wild-type littermate controls were produced by crossing transgenic mice carrying the tetracycline-controlled transcriptional transactivator tTA driven by the CaMKII $\alpha$ promoter (tTA) with transgenic mice carrying the Ap $\mathrm{oa}_{1}$ transgene driven by the tet-Opromoter (tet-O-Ap oa A $_{1}$, as described previously (Isiegas et al., 2008). All mouse lines were bred onto a C57B/6J background for more than 10 generations. The double transgenics obtained by crossing the two transgenic lines are referred to as $\mathrm{Ap} \mathrm{oa_{1 }}$ transgenic mice. The breeder mice were housed in standard shoebox cages, with standard chow and water available ad libitum. Mouse litters for behavioral testing were produced one litter per large gang cage containing standard bedding supplemented with cloth nesting squares. To avoid early life stress induced by cage changes, the litters were left undisturbed without change of bedding until the day of weaning [postnatal day 21 (P21)], when they were genotyped by PCR analysis of tail biopsies and tagged with metal ear tags. tTA heterozygotes and tet-O-Ap oa ${ }_{1}$ heterozygotes were genotyped by PCR (Isiegas et al., 2008). Genotypes were coded such that the experimenter carrying out subsequent testing and data analyses was unaware of them. We used 2- to 3-month-old male bitransgenic mice, and tTA, tet-O-Ap $\mathrm{oa}_{1}$, and wild-type (WT) littermate male mice as controls for all our experiments. The cages of the behavioral test animals were changed once a week. C57BL/6J mice were from The Jackson Laboratory.

Drugs. Octopamine (1 mg/kg, i.p.) (Sigma) was dissolved in $0.9 \%$ saline and injected once daily. The last dose was administered $24 \mathrm{~h}$ before the mice underwent behavioral testing or were killed for biochemical assays and examination of neurogenesis. For acute treatment, mice were injected with octopamine or $0.9 \%$ saline in the morning of the day before testing. For chronic treatment, mice were treated daily with octopamine or saline for 2 weeks. Fluoxetine ( $10 \mathrm{mg} / \mathrm{kg}$; Sigma) or saline was injected intraperitoneally once daily for $21 \mathrm{~d}$. Doses were chosen based on previous studies of the actions of ADs (Sairanen et al., 2005; Nakagawa et al., 2002a,b).

Immunohistochemistry and Western blot analysis. Mice were perfused with 4\% paraformaldehyde in PBS for $20 \mathrm{~min}$ and processed for histology. The brains were rapidly removed and immediately frozen and stored at $-70^{\circ} \mathrm{C}$. Serial sections ( $35 \mu \mathrm{m} / \mathrm{section}$ ) were cut coronally through the entire anteroposterior extension of the hippocampi. For bromodeoxyuridine (BrdU) immunolabeling, sections were processed as described (Son et al., 2003). For other types of immunofluorescent labeling, sections were incubated in $10 \%$ normal goat serum and $0.3 \%$ Triton $\mathrm{X}-100$ for $1 \mathrm{~h}$ at room temperature. They were then incubated overnight at $4^{\circ} \mathrm{C}$ in $0.1 \mathrm{M}$ PBS, pH 7.4, containing $0.3 \%$ Triton X-100 (PBST) and one of the following primary antibodies: rabbit polyclonal antiphosphorylated CREB (1:200, Affinity BioReagents), rabbit polyclonal anti-VEGF (1:200, Santa Cruz Biotechnology) and rabbit polyclonal anti-BDNF (1:200, Santa Cruz Biotechnology). Sections were then washed in PBST, placed in secondary antibody (1:1000 biotinylated don- key anti-mouse; Jackson ImmunoResearch Laboratories), amplified with the avidin-biotin complex (Vectastain ABC Elite; Vector Laboratories), and visualized with a detection solution $(0.25 \mathrm{mg} / \mathrm{ml}$ diaminobenzidine $)$ (Saveen Biotech). For doublecortin (DCX), sections were washed after antigen retrieval (sodium citrate, $\mathrm{pH} 9.0$ ), incubated for $30 \mathrm{~min}$ in $0.6 \%$ $\mathrm{H}_{2} \mathrm{O}_{2}$, blocked with $3 \%$ normal donkey serum in $0.1 \%$ Triton X-100, and incubated in polyclonal goat-anti DCX (1:250; Santa Cruz Biotechnology) overnight at $4^{\circ} \mathrm{C}$. The sections were then washed in PBS, placed in the secondary antibody and processed as above. Rat polyclonal BrdU (1:300, Abcam), mouse monoclonal anti-CaMKII $\alpha$ (1:300, Santa Cruz Biotechnology) and rabbit monoclonal anti-RECA (1:50, Cell Science, Netherlands) were also used. For these primary antibodies, samples were incubated at room temperature for an additional $1 \mathrm{~h}$ with secondary antibodies conjugated to fluorescein isothiocyanate, cyanin 3 (1:200, Jackson ImmunoResearch), DTAF (1:400, Jackson ImmunoResearch), Alexa 488 (1:500, Molecular Probes) or Alexa 546 (1:500, Molecular Probes). The samples were then washed with PBS, and coverslipped in DAPI and Vectashield mounting medium (Vector Laboratories). Fluorescent signals were detected using a confocal laser-scanning microscope (Zeiss) and fluorescence microscope (Nikon), which allowed simultaneous evaluation of up to four separate fluorophores. When we also needed to observe the nuclei, the cells were counterstained with DAPI in addition to the four immunological markers. For Western blot analysis, cells were prepared as previously described (Kim et al., 2004). The primary antibodies used for Western blot analysis were rabbit polyclonal anti-phosphorylated CREB (1:200, Affinity BioReagents), rabbit polyclonal anti-CREB (1:1000, Cell Signaling Technology), rabbit polyclonal anti-VEGF (1:200, Calbiochem), rabbit polyclonal anti-HIF-1 $\alpha$ (1:500, Santa Cruz Biotechnology), and rabbit monoclonal anti-RECA (1:50, Hycult biotechnology).

Quantification of images of immunohistochemistry and Western blotting. To measure the intensity of immunoreactivity in the granule cell layer (GCL) of the DG, images were acquired with a digital camera (Nikon E800) and analyzed using an image analysis program (AnalySIS version 3.0, Soft Image Analysis System GmBH). In each image, a ROI (region of interest), which represented the DG, was determined by free hand drawing, and mean optical values in each ROI were measured. Results represent the ratio of the intensity, which was computed by dividing the mean optical value of a region in $\mathrm{Ap} \mathrm{oa}$ mice by the corresponding value in control mice. Generally, four to eight sections of each hippocampus from control and $\mathrm{Ap} \mathrm{oa_{1 }}$ transgenic mice were averaged to determine a value for an animal. For Western blots, we quantified proteins on scanned images and calibrated the relative level of phosphorylated CREB or VEGF versus total CREB or $\beta$-actin in $\mathrm{Ap} \mathrm{oa}_{1}$ mice to that of control mice treated with octopamine.

BrdU administration. We injected mice with $\operatorname{BrdU}(50 \mathrm{mg} / \mathrm{kg}$, i.p.; Sigma) at a concentration of $15 \mathrm{mg} / \mathrm{ml}$. For acute experiments, mice were injected with BrdU or $0.9 \%$ saline at the time of octopamine treatment on the morning of the day before testing or killing. For chronic experiments, BrdU or saline was injected once daily for the first $3 \mathrm{~d}$ or the last $3 \mathrm{~d}$ of the $14 \mathrm{~d}$ octopamine treatment for examining the proliferation and survival of neurons, respectively.

Cell counting. We counted $\mathrm{BrdU}^{+}, \mathrm{DCX}^{+}$or $\mathrm{RECA}^{+}$cells in the SGZ using a fluorescence microscope (Nikon) at $400 \times$, video camera and LEICA IM50 software in six to eight coronal $30 \mu \mathrm{m}$ sections spaced 400 $\mu$ m apart per mouse. All BrdU ${ }^{+}, \mathrm{DCX}^{+}$or $\mathrm{RECA}^{+}$cells in the GCL and subgranular zone (SGZ) were counted in each section by an experimenter blinded to the study code. Data are expressed as the average number of immunoreactive cells and reported as mean \pm SEM. We used the unpaired, two-sided Student's $t$ test for statistical analysis.

Construction of VEGF promoter reporter plasmids. The mouse VEGF promoter was cloned into a pGL3-basic vector and the resulting construct was designated $\mathrm{pVEGF}(\mathrm{W})(-1852$ to $\sim-233)$. Two deletion mutants, containing the putative CRE1 (5'-TGGCGGCA-3', -1785 to $\sim-1778$ ) and CRE2 (5'-TGAGGTGG-3', -1032 -1025), respectively, were amplified from mouse genomic DNA by PCR, based on the sequences previously reported (Accession No. U41383) (Shima et al., 1996). The mouse VEGF promoter containing only CRE1 was generated by ligation of the VEGF promoter $(-1852$ to $\sim-233)$ after removing the 
CRE2 site by digestion with BstXI. To generate the CRE-negative VEGF promoter control, the VEGF promoter containing CRE1 and CRE2 sites $(-1852$ to $\sim-233)$ was digested with XhoI and BstXI. After removal of the XhoI and BstXI fragments, the promoter DNA was blunt-end ligated after carrying out a Klenow fill-in reaction. We verified the products before cloning them into pGL3-basic plasmid (Promega).

Transfection of HEK293 cells and luciferase assay. Reporter plasmids were introduced together with expression plasmids and pCMV $\beta$ gal (Stratagene) into HEK293 cells with lipofectamine according to the manufacturer's protocol (Invitrogen). The entire amino acid coding region of Ap oa ${ }_{1}$ subcloned into pcDNAIII (Invitrogen) was used (Chang et al., 2000). Luciferase assays were performed as specified by the manufacturer (BD Biosciences) and the level of transcriptional activation was determined as the ratio of the luciferase activity from each treatment relative to the luciferase activity from nonstimulated cell extracts. Reverse transcriptase (RT)-PCR analysis of Ap oa ${ }_{1}$ was done as described previously (Isiegas et al., 2008). pCMV2-CREB (a rat CREB expression plasmid) and a DN-CREB with the serine133 phosphorylation site mutated to alanine were generously provided by Professor Pyeung-Hyeun Kim (Kangwon University, Korea).

Real-time PCR. RNA was extracted from hippocampi with Trizol reagent (Molecular Research Center). Reverse transcription was performed with Improm-II (Promega). PCR was performed on an iCycler iQ Multi-Color Real-Time PCR Detection System (Bio-Rad Laboratories). The primers used to amplify cDNAs of human VEGF165, mouse VEGF164, and BDNF are described in supplemental materials, available at www.jneurosci.org. The housekeeping gene GAPDH was used as a control. Expression of each gene was normalized to the amount of GAPDH to calculate relative transcript levels. Normalized expression values were averaged, and average fold changes were calculated.

Electrophoretic mobility shift assay. The sequences of oligonucleotides used were as follows: consensus CRE: $5^{\prime}$-AGAGATTGCCTGACGTCAGAGAGCTAG-3', VEGFCRE2:5' -TAGTGTGTTTGTGAGGTGGGGGAGAAAGCC-3', and mutant CRE2: 5'-TAGTGTGTTTGTGAGACGGGGGAGAAAGCC-3'. Electrophoretic mobility shift assay (EMSA) probes were generated by end-labeling 4.0 pmol of doublestranded oligonucleotides with $10 \mu \mathrm{Ci}\left[\gamma^{-}{ }^{32} \mathrm{P}\right] \mathrm{ATP}(3000 \mathrm{Ci} / \mathrm{mmol})$ (PerkinElmer Inc.) using T4 kinase (Promega). For each reaction, 40 fmol of labeled oligonucleotide was incubated with $5 \mu \mathrm{g}$ of nuclear extract or $1 \mu \mathrm{g}$ of recombinant human CREB (rhCREB) (Biosource International Inc.) in binding buffer [ $50 \mathrm{~mm}$ Tris- $\mathrm{HCl}, \mathrm{pH} 7.5,0.25 \mathrm{mg}$ of poly(dI-dC), $5 \mathrm{~mm} \mathrm{MgCl}_{2}$, $2.5 \mathrm{~mm}$ EDTA, $250 \mathrm{~mm} \mathrm{NaCl}, 2.5 \mathrm{~mm}$ DTT, $20 \%$ glycerol] for $20 \mathrm{~min}$ at room temperature. For competition assays, a 100-fold molar excess of unlabeled double-stranded oligonucleotide was added to each reaction. For supershift assays, $0.5 \mu \mathrm{l}$ of anti-CREB (Cell Signaling Technology) or normal rabbit IgG was added after the binding reaction and further incubated for $20 \mathrm{~min}$ at room temperature. Samples were resolved on $6 \%$ nondenaturing polyacrylamide gels in $0.5 \times \mathrm{TBE}$ buffer ( $25 \mathrm{~mm}$ Tris, $0.5 \times$ borate, and $0.5 \mathrm{~mm}$ EDTA). The gels were dried and exposed to film.

Chromatin immunoprecipitation assay. Mice were killed $3 \mathrm{~h}$ after the last injection of octopamine, and hippocampal tissues were quickly dissected and processed for chromatin immunoprecipitation (ChIP). ChIP assays were performed as specified with the Upstate Biotechnology ChIP kit (Upstate Biotechnology), modified by using published methods (Wells and Farnham, 2002). Anti-CREB (1:200, Cell Signaling) was used. Immunoprecipitated DNA samples were resuspended in $\mathrm{H}_{2} \mathrm{O}$, and fractions were used for semiquantitative PCR (TC-312, TECHNE) or realtime PCR (iCycler, Bio-Rad). Specific primers for CRE2 were designed to amplify the mouse VEGF-A promoter region. The primer sequences are given in supplemental materials, available at www.jneurosci.org. Input or total DNA (nonimmunoprecipitated) and immunoprecipitated DNA were PCR amplified in triplicate in the presence of SYBR Green (Applied Biosystems). Ct values for each sample were obtained using Sequence Detector 1.1 software. Real-time PCRs, run in triplicate for each brain sample, were performed independently at least twice. Nonspecific antibody immunoprecipitates were used as controls for ChIP specificity. Data are normalized to the amount of DNA precipitated with nonspecific antibody and are shown relative to the level in WT mice given octopamine.

shRNA preparation and transfection. We used commercial shRNA constructs for VEGF (Sigma) and a control nontargeting shRNA (pll3.7, ATCC) (Rubinson et al., 2003). Optimal conditions involved transfecting mouse hippocampal neuronal cells, maintained in DMEM at $80 \%$ confluence in six-well plates, using $1 \times 10^{6}$ VEGF shRNA and lipofectamine (Invitrogen). Cells were collected every $96 \mathrm{~h}$ after transfection and processed for RT-PCR for VEGF. We randomly assigned 8-week-old Ap oa ${ }_{1}$ transgenic mice to receive lenti-shVEGF or lenti-EGFP and injected each group with $3 \mu \mathrm{l}$ of lenti-shVEGF or lenti-EGFP vector $(1 \times$ $10^{6}$ particles) bilaterally into the dorsal hippocampus at the stereotaxic coordinates -2.0 anteroposterior (AP), \pm 1.5 mediolateral (ML), -2.4 dorsoventral (DV) ( $\mathrm{mm}$ from bregma, horizontal skull). After 2 weeks, we injected mice with octopamine (1 mg/kg, i.p.) for 2 weeks. Littermate control mice were split into two groups and treated in the same way. A separate group of C57BL/6J mice was split into three groups and treated with lenti-EGFP, lenti-shVEGF or vehicle before fluoxetine $(10 \mathrm{mg} / \mathrm{kg}$, i.p.) treatment for $21 \mathrm{~d}$. We kept these mice in standard housing for 2 more weeks before behavioral testing or perfusing them and staining hippocampal sections.

Adeno-VEGF vector construction and packaging. The adeno-VEGFGFP plasmid construction and viral packaging are described previously (Kim et al., 2008). We randomly assigned 7-week-old C57BL/6J mice to receive adeno-VEGF or adeno-EGFP. We injected $2 \mu$ l of adenoviral vectors $\left(3 \times 10^{9}\right.$ particles $)$ bilaterally into the dorsal hippocampus of mice at the stereotaxic coordinates $-2.0 \mathrm{AP}, \pm 1.5 \mathrm{ML},-2.4 \mathrm{DV}(\mathrm{mm}$ from bregma, horizontal skull).

Behavioral assessments. Behavioral testing was performed on male mice aged 2-3 months during the first $6 \mathrm{~h}$ of the dark phase. Ap oa mice were compared with their WT littermates. The order of the behavioral tests was as follows: novelty-suppressed feeding test (NSFT), sucrose consumption test (SCT), and FST over a $2 \mathrm{~d}$ period. The open field test (OFT) and elevated plus maze test (EPMT) were performed the next day. Otherwise, each mouse was used in one test only. The behavior of the mice was videotaped in the holding room under dim red light and analyzed with both real-time and off-line versions of EthoVision 3.1 (Noldus Information Technology).

FST. We placed the animals individually in cylinders (height $30 \mathrm{~cm}$, diameter $15 \mathrm{~cm}$ ) filled with 12 -cm-deep water (temperature $22 \pm 1{ }^{\circ} \mathrm{C}$ ) for $6 \mathrm{~min}$, and recorded the total period of immobility during the last 4 min (Porsolt et al., 1977).

NSFT. We presented mice deprived of food for $24 \mathrm{~h}$ with food pellets placed in the center of a bright plastic box $(50 \times 50 \times 20 \mathrm{~cm})$. We measured latency before beginning eating as previously described (Santarelli et al., 2003).

SCT. Mice were habituated for $48 \mathrm{~h}$ to $1 \%$ sucrose (Sigma), and, after a $12 \mathrm{~h}$ deprivation period, their preference for sucrose (1\%) or water (identical bottles) was measured for $1 \mathrm{~h}$. The amount of the sucrose solution or water consumed was determined by weighing the bottles.

OFT. The open-field apparatus consisted of a white Plexiglas box $(50 \times 50 \times 22 \mathrm{~cm})$ with 16 squares $(12 \times 12 \mathrm{~cm})$ painted on the floor $(12$ outer and 4 inner). Each mouse was placed in the center of the apparatus to initiate a 10-min test session, and their movements were recorded.

EPMT. On an elevated crossbar $(30 \mathrm{~cm}$ per arm $\times 5 \mathrm{~cm}$ wide $\times 40 \mathrm{~cm}$ tall) with two walled $(20 \mathrm{~cm}$, transparent) and two open arms (Crestani et al., 1999), mutant mice and littermate controls were placed onto the center square and videotaped for $5 \mathrm{~min}$. The number of entries and the total time spent on closed and open arms were recorded.

Chronic unpredictable stress procedure. Adenoviral vector injected C57BL/6J mice were exposed to a sequence of mild and unpredictable stressors for $21 \mathrm{~d}$. The stressors used were: cage rotation, light on, light off, isolation, swim stress, cold stress, food or water deprivation, wet bedding, stroboscope, cage tilt, odor exposure, and group housing. This sequence of stressors has previously been shown to induce depression (Griebel et al., 2002).

Statistical analyses. All values included in the figure legends represent mean \pm SEM. Statistical analysis of the biochemical experiments was 
a

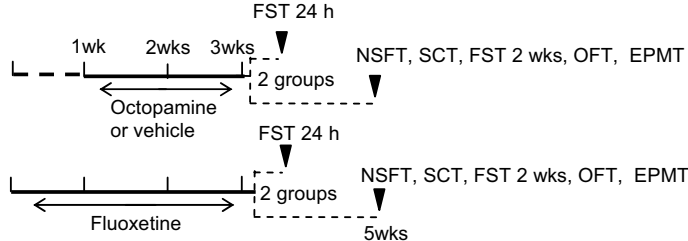

WT littermates + octopamine

WT littermates + fluoxetine

Ap oa $a_{1}+$ vehicle

Ap oa ${ }_{1}+$ octopamine

b

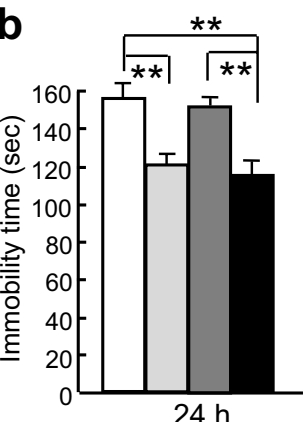

C

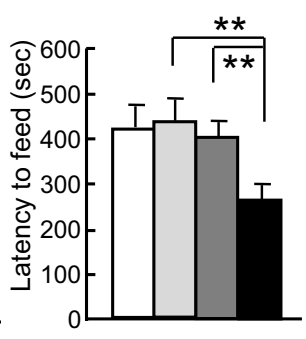

g

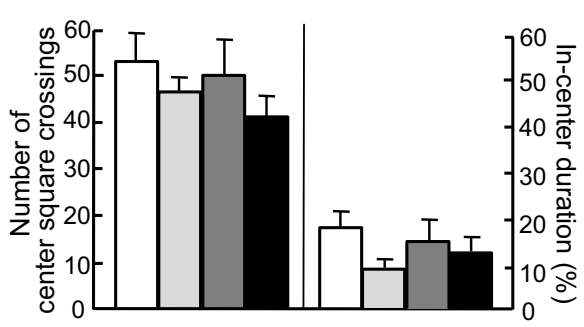

d

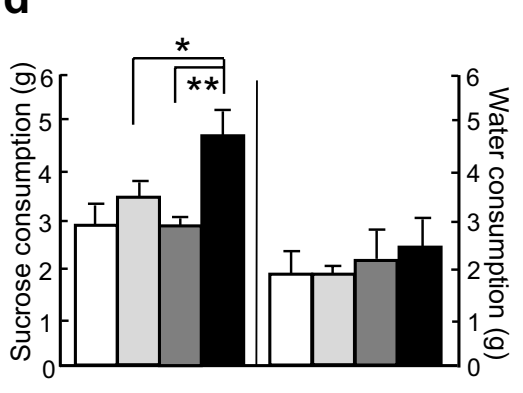

h

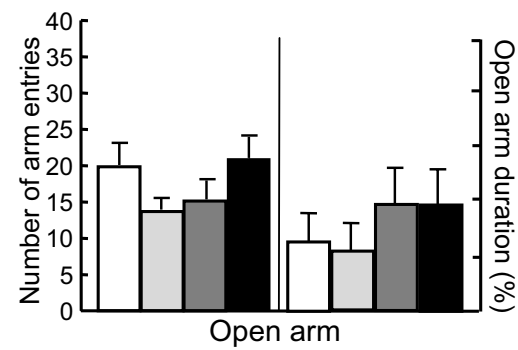

e

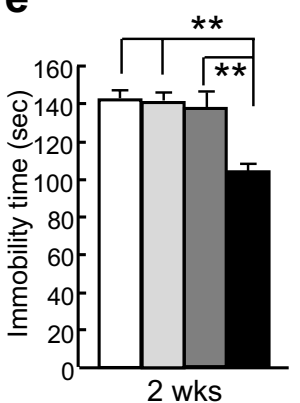

i

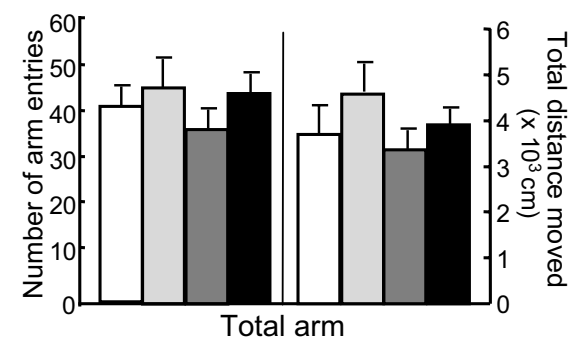

Figure 1. Antidepressant-like behaviors induced by chronic octopamine treatment in Ap oa 1 mice. $\boldsymbol{a}$, Experimental design. Mice treated with chronic octopamine for 2 weeks or fluoxetine for 3 weeks were divided into two groups for behavioral measurements. $\boldsymbol{b}$, FST. Immobility time was measured $24 \mathrm{~h}$ after the last injection of drug $(n=13-16$ animals per group). Significant effects of octopamine are seen for genotype (Ap oa, vs WT littermates, ${ }^{* *} p<0.01$, two-way ANOVA) and for treatment in Ap oa ${ }_{1}$ mice (vehicle vs octopamine, ${ }^{* *} p<0.01$, two-way ANOVA). Significant effects of fluoxetine in WT littermates are seen ( ${ }^{* *} p<0.01$, two-way ANOVA). c, NSFT. Latency to feed was measured 2 weeks after the last injection of chronic octopamine or fluoxetine $(n=8-10$ animals per group). Chronic octopamine reduced latency to feed in Ap oa 1 mice compared with WT mice that received fluoxetine or Ap oa $a_{1}$ mice that received vehicle $\left({ }^{* *} p<0.01\right.$, two-way ANOVA). Fluoxetine did not reduce latency in WT littermates (octopamine vs fluoxetine, $p>0.05$, two-way ANOVA). $\boldsymbol{d}, \mathrm{SCT}$. The test was performed 2 weeks after octopamine or fluoxetine treatment ( $n=$ 13-16 animals per group). Chronic octopamine in Ap oa 1 mice increased sucrose consumption compared with WT mice treated with fluoxetine $\left({ }^{*} p<0.05\right.$, two-way ANOVA) or Ap oa 1 mice treated with vehicle ${ }^{* *} p<0.01$, two-way ANOVA). There was no difference in water consumption between groups ( $\left.p>0.05\right) \cdot \boldsymbol{e}$, FST. Immobility time was measured 2 weeks after the last injection of drug ( $n=13-16$ animals per group). Significant effects of octopamine are seen for genotype (Ap oa 1 vs WT littermates, ${ }^{* *} p<0.01$, two-way ANOVA) and for treatment in Ap oa ${ }_{1}$ mice (vehicle vs octopamine, ${ }^{* *} p<0.01$, two-way ANOVA). Significant effects of fluoxetine in WT littermates were not seen ( $p>0.05$, two-way ANOVA).f, 0 FT ( $n=16-18$ animals per group). The total distance moved in the box was similar in all groups ( $p>0.05$ vs WT mice given octopamine, two-way ANOVA). $\boldsymbol{g}, 0 \mathrm{FT}$ ( $n=16-18$ animals per group). The number of center square crossings (left), and the distance moved in the center zone (right) expressed as a percentage of the total distance moved in the box were similar in all groups ( $p>0.05$ vs WT mice given octopamine, two-way ANOVA). $\boldsymbol{h}$, EPMT ( $n=16-18$ animals per group). The number of visits to the open arms and time spent in the open arms, expressed as a percentage of the total time spent in the open and closed arms, did not differ among groups ( $p>0.05$ vs WT mice given octopamine, two-way ANOVA). $i$, Locomotor activity in the EPMT. Total arm entries and total distance moved were not different $(p>0.05$ vs WT mice given octopamine, two-way ANOVA).

performed using ANOVA or the unpaired, two-tailed $t$ test (SPSS 16.0). We used a one- or two-way ANOVA to analyze the FST, the NSFT, the sucrose consumption, the open field and elevated plus maze tests, and determined the differences between individual treatment groups using the Tukey's test for post hoc comparisons (SPSS 16.0). Null hypotheses were rejected at the 0.05 level.

\section{Results}

Antidepressant-like phenotype in Ap oa transgenic mice The functionality of the Ap oa ${ }_{1}$ receptor was previously assessed by measuring cAMP levels in the hippocampus from Ap oa ${ }_{1}$ mice in vivo. Intraperitoneal injection of octopamine $(1 \mathrm{mg} / \mathrm{kg})$ resulted in cAMP elevation in the hippocampus of Ap oa transgenic mice (Isiegas et al., 2008). This indicates that octopamine readily crosses the blood-brain barrier. Based on this evidence, we evaluated the effect of Ap oa $\mathrm{a}_{1}$ activation on antidepressive behavior using conditional knock-in $\mathrm{Ap} \mathrm{oa}_{1}$ mice under a chronic paradigm involving 14 daily injections of octopamine $(1 \mathrm{mg} / \mathrm{kg})$. The chronic paradigm was used because the half-lives of trace amines, including octopamine, in the CNS are extremely short ( 20 s) (Durden and Philips, 1980; Paterson et al., 1990). Also, antidepressive behavior requires chronic administration of ADs (Santarelli et al., 2003), which is accompanied by activation of cAMP signaling, manifested by enhanced phosphorylation of CREB (Nibuya et al., 1996; Thome et al., 2000; Blom et al., 2002; Nakagawa et al., 2002a; Tiraboschi et al., 2004).

As a criterion for antidepressive activity we used responsiveness in the FST (Lucki, 1997; Dulawa et al., 2004). To reflect the delayed onset of AD action under clinical conditions, we used the chronic paradigm of 14 d' octopamine treatment (Fig. 1a). We found a significant reduction in the immobility time of the Ap oa transgenic mice treated with octopamine compared with WT mice treated with octopamine or Ap oa ${ }_{1}$ mice treated with vehicle 
when the animals were tested $24 \mathrm{~h}$ after the last octopamine treatment (Ap oa 1 mice treated with octopamine, $117.3 \pm 12.6 \mathrm{~s}$, compared with WT mice treated with octopamine, $158.75 \pm$ $7.15 \mathrm{~s}, p=0.0035$; compared with Ap oa $\mathrm{o}_{1}$ mice treated with vehicle, $150.5 \pm 4.24 \mathrm{~s}, p=0.0021$; two-way ANOVA, $F_{(2,22)}=$ 6.882; Tukey's post hoc) (Fig. $1 b$ ). This effect was similar to that seen with WT mice exposed to chronic fluoxetine for $21 \mathrm{~d}$ (WT mice treated with fluoxetine, $121.83 \pm 7.95 \mathrm{~s}$ vs Ap oa ${ }_{1}$ mice treated with octopamine, two-way ANOVA, Tukey's post hoc: $p=0.8)($ Fig. $1 b)$

To assess whether our results on the FST in Ap oa ${ }_{1}$ mice can be generalized as an antidepressant-like phenotype, a separate group of mice were tested for two depression-related behaviors, the NSFT and the SCT, within a $2 \mathrm{~d}$ period 2 weeks after the chronic octopamine or fluoxetine treatment (Fig. 1a). NSFT is a behavior paradigm which is sensitive to chronic AD drug treatment (Santarelli et al., 2001; Warner-Schmidt and Duman, 2007). When NSFT was performed 2 weeks after the chronic octopamine treat-

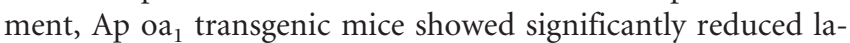

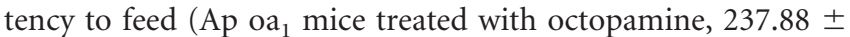
$29.12 \mathrm{~s}$, compared with WT mice treated with fluoxetine, $505.90 \pm 37.55 \mathrm{~s}, p=0.004$; compared with Ap oa ${ }_{1}$ mice treated with vehicle, $407.33 \pm 40.86, p=0.00032$; two-way ANOVA, $F_{(2,22)}=4.976$; Tukey's post hoc) (Fig. 1c). In fact there was no difference in latency between WT mice given chronic fluoxetine and Ap oa ${ }_{1}$ mice given vehicle (Tukey's post hoc: $p=0.97$ ) (Fig. $1 c)$. SCT is a paradigm that measures an animal's responsiveness to a natural reward (Adachi et al., 2008). A loss of sensitivity to reward has been suggested as an important feature of depression. The SCT also showed that octopamine treatment increased the sucrose consumption in the Ap $\mathrm{oa}_{1}$ mice compared with WT mice given fluoxetine or Ap oa $\mathrm{a}_{1}$ mice given vehicle (Ap oa mice treated with octopamine, $4.6 \pm 0.5 \mathrm{~g}$, compared with WT mice treated with fluoxetine, $3.5 \pm 0.3 \mathrm{~g}, p=0.044$; compared with Ap $\mathrm{oa}_{1}$ mice treated with vehicle, $3.0 \pm 0.1 \mathrm{~g}, p=0.0091$; two-way ANOVA, $F_{(2,14)}=4.755$; Tukey's post hoc:) (Fig. $1 d$ ). The results of these three behavioral experiments indicated that there might be an 'antidepressant-like phenotype' for Ap oa ${ }_{1}$ mice receiving octopamine.

To confirm whether the behavioral change was long-lasting, we measured immobility time in the FST 2 weeks after the chronic octopamine or fluoxetine treatment. Ap oa mice that received octopamine showed a reduction in immobility time compared with WT littermates that received fluoxetine or Ap oa mice that received vehicle (Ap oa ${ }_{1}$ treated with octopamine, $105.88 \pm 6.78 \mathrm{~s}$, compared with WT mice treated with fluoxetine, $142.75 \pm 2.74 \mathrm{~s}, p=0.004$; compared with Ap oa ${ }_{1}$ mice treated with vehicle, $140.53 \pm 4.02 \mathrm{~s}, p=0.0074$; two-way ANOVA, $F_{(2,32)}=11.52$; Tukey's post hoc) (Fig. 1e). However, Tukey's multiple comparison test revealed that there was no significant difference in the immobility time of the Ap oa mice between $24 \mathrm{~h}$ and 2 weeks, indicating that chronic activation of Ap oa has persistent effects on behavioral performance in the FST. The persistent effect was not seen in WT littermates that received fluoxetine. Immobility time in the FST was also reduced in the Ap oa transgenic mice given octopamine acutely (30 min before test) but the effect did not last for $>2$ weeks (supplemental Fig. 1, available at www.jneurosci.org as supplemental material). These results indicate that the chronic activation of $\mathrm{Ap} \mathrm{oa}$ has persistent effects on behavioral performance, and that activation of Ap $\mathrm{oa}_{1}$ can mimic the antidepressive effects of $\mathrm{AD}$ treatment.

To determine whether the antidepressant-like phenotype is accompanied by a decrease in anxiety, we evaluated $\mathrm{Ap} \mathrm{oa}$ mice for anxiety levels using two different paradigms. In the OFT, the distance moved in the open field apparatus was measured for WT mice treated with octopamine or fluoxetine and Ap oa mice treated with octopamine or vehicle. All four groups of mice moved similar total distances in the open field (Fig. 1f), and displayed similar numbers of center square crosses and percentages of time in the center zone (Fig. $1 g$ ). Results from the EPMT showed that there were no differences in either number of entries into the open arms or percentage time in the open arms for Ap $\mathrm{oa}_{1}$ mice receiving octopamine and other groups (Fig. $1 \mathrm{~h}$ ). The locomotor activity was not different, as overall activity in the total arm entries and total distance moved was not different among the four groups (Fig. 1h,i). These results indicate that chronic activation of Ap $\mathrm{oa}_{1}$ did not alter levels of anxiety.

\section{Inducible enhancement of hippocampal neurogenesis in Ap oa $_{1}$ mice}

Because ADs increase the CAMP-CREB cascade and CREB plays a role in hippocampal neurogenesis in the adult brain (Gass and Riva, 2007; Nakagawa et al., 2002a,b), we investigated whether Ap $\mathrm{oa}_{1}$ activation led to proliferation of neural progenitor cells (Fig. $2 a$ ). We quantitated the number of newborn cells in the DG of the adult hippocampi of Ap oa ${ }_{1}$ mice. When Ap oa transgenic mice were chronically treated with octopamine, the number of 5-bromo-2-deoxyuridine-positive $\left(\mathrm{BrdU}^{+}\right)$cells increased twofold relative to $\mathrm{Ap} \mathrm{oa}$ mice given vehicle (vehicle, $1289 \pm 95$ vs octopamine, $2611 \pm 323$, Student's $t$ test, $p=0.000925$ ) (Fig. $2 b, g)$ and there was no such effect in other controls including WT littermates and single transgenics (supplemental Fig. 2, available at www.jneurosci.org as supplemental material). Given the similarity in behaviors and neurogenesis of WT and single transgenic littermates regardless of whether they received octopamine and of Ap oa ${ }_{1}$ mice receiving vehicle, we used WT littermates as controls in the following experiments.

Moreover, the chronic octopamine treatment selectively increased the survival of newborn DG cells $\sim 2$-fold in Ap oa 1 mice (vehicle, $828 \pm 173$ vs octopamine, $1603 \pm 248$, Student's $t$ test, $p=0.00016$ ) (Fig. $2 d, g$ ), which was confirmed by positive immunopositivity for DCX, a marker for neuronal progenitors of developing and adult brains (Couillard-Despres et al., 2005) (Ap $\mathrm{oa}_{1}$ mice treated with vehicle, $2985 \pm 91$ vs octopamine, $4511 \pm$ 407 , Student's $t$ test, $p=0.00023$ ) (Fig. $2 e, g$ ). The majority of the $\mathrm{BrdU}^{+}$cells were neuronal, as detected by BrdU-DCX colocalization (Fig. 2f). Evidently, baseline neurogenesis is little affected by the presence of the Ap oa ${ }_{1}$ transgene, but the activation of the transgene by chronic octopamine treatment markedly stimulates neurogenesis. The increased survival of $\mathrm{BrdU}^{+}$cells was still evident 2 weeks after chronic octopamine treatment (supplemental Fig. 3, available at www.jneurosci.org as supplemental material), indicating that the effects of Ap oa ${ }_{1}$ activation on neurogenesis and behaviors are long-lasting.

\section{Chronic octopamine treatment induces phosphorylation of CREB and neuronal VEGF}

We next tested whether the increases in antidepressive behavior and hippocampal neurogenesis in $\mathrm{Ap} \mathrm{oa}$ mice were due to more efficient CREB activation by chronic daily injection of octopamine than acute octopamine treatment. Of the several regions in which the Ap oa ${ }_{1}$ transgene is expressed (supplemental Fig. 4, available at www.jneurosci.org as supplemental material) (Isiegas et al., 2008), we chose to focus on the hippocampus for two reasons: (1) high levels of octopamine-induced phosphorylated CREB (pCREB) expression are observed in this region (Isiegas et 

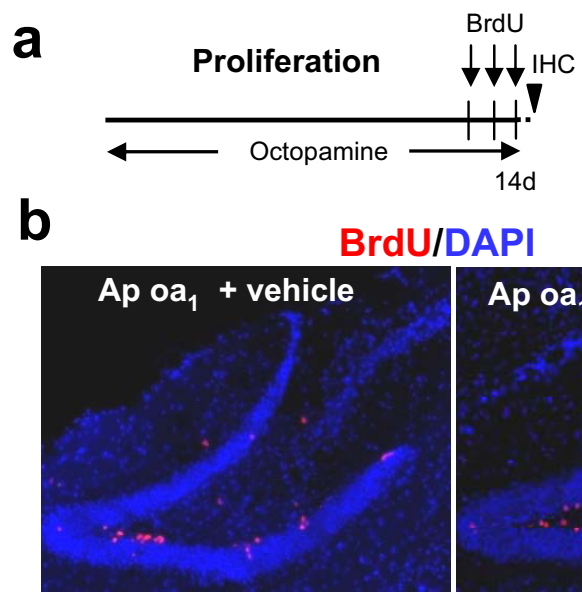

b

e

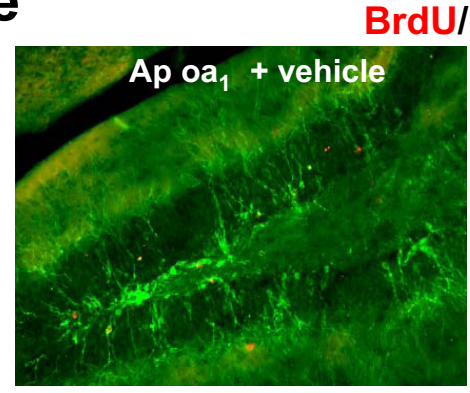

c

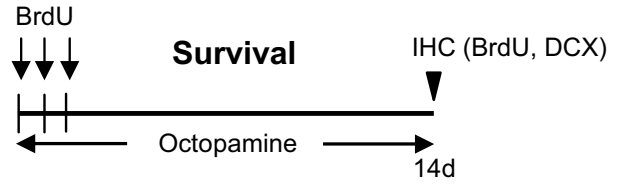

d
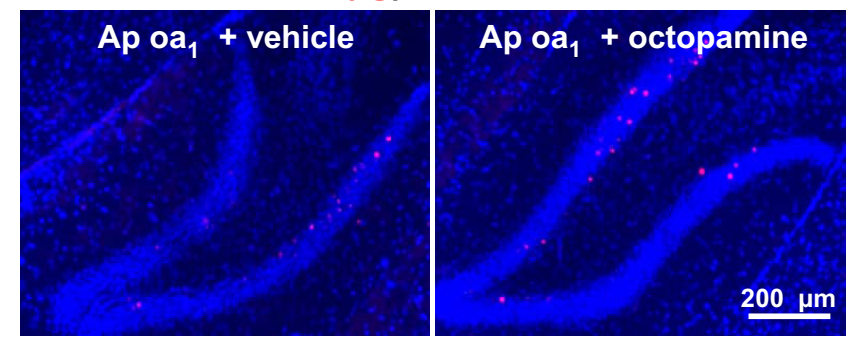

BrdU/DAPI
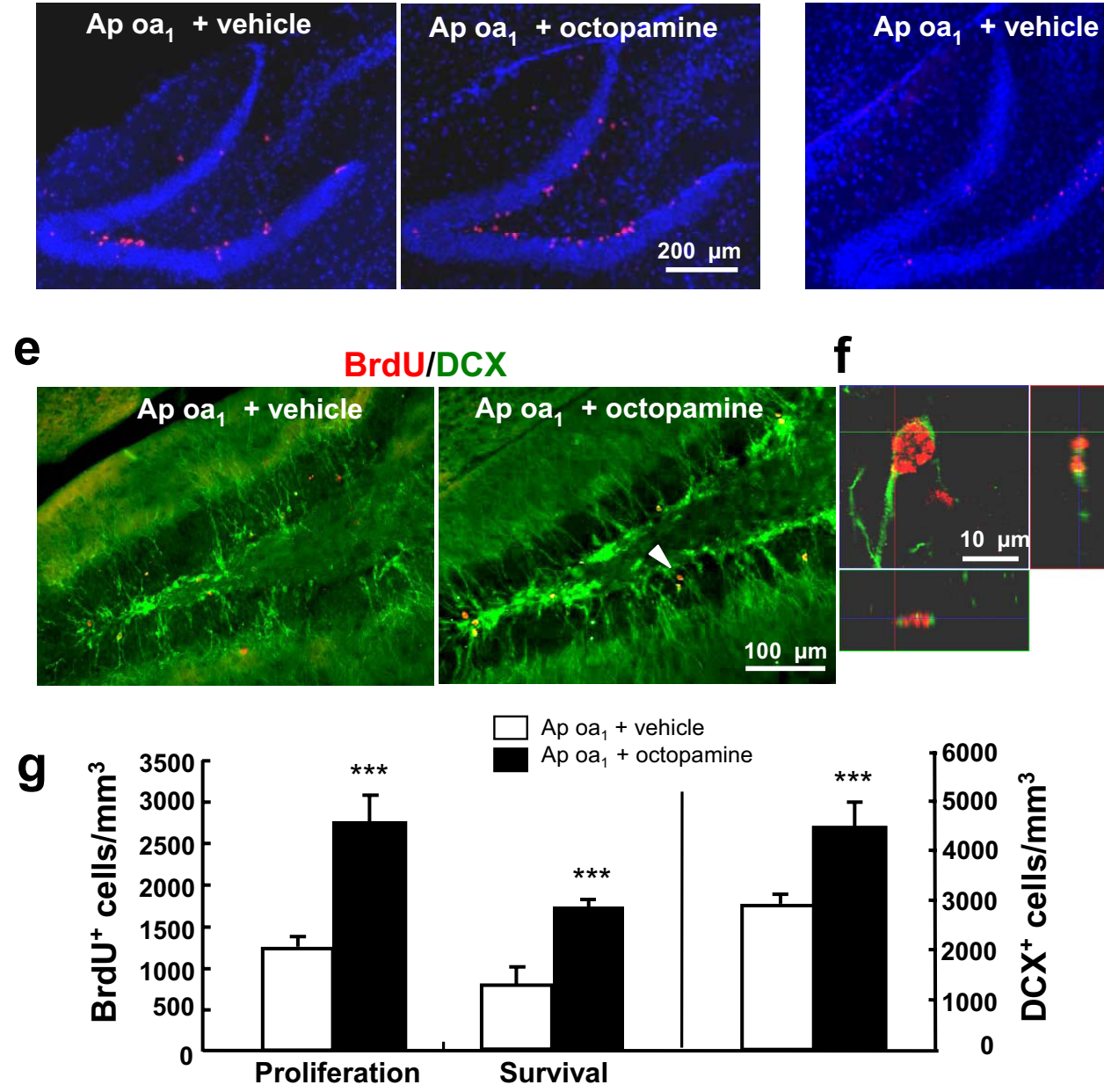

Figure 2. Increased octopamine-induced neurogenesis in Ap oa transgenic mice. $\boldsymbol{a}$, Experimental design for proliferation studies. $\boldsymbol{b}, 0 \mathrm{ctopamine}$ increased proliferation in the SGZ of the

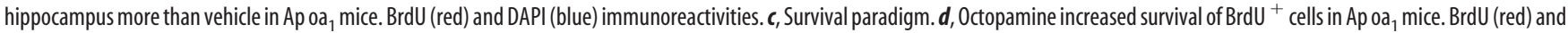
DAPI (blue) immunoreactivities. $\boldsymbol{e}$, Labeling of the immature neuronal marker DCX (green) in the DG when mice are subjected to the survival paradigm of $c$. $f$, High-power confocal image of a cell (arrowhead in $\boldsymbol{e}$ ) coexpressing BrdU (red) and DCX (green). The bottom and right panels show images merged across the $x$-and $z$-axis, respectively. $\boldsymbol{g}$, Quantification of BrdU ${ }^{+}$cells in the SGZ after proliferation ( ${ }^{* * *} p<0.001$, Student's $t$ test; $n=10-13$ animals per genotype) and survival paradigm ( ${ }^{* * *} p<0.001$, Student's $t$ test; $n=7-10$ animals per genotype). Quantification of $D C X{ }^{+}$ cells in the DG of $e$. Octopamine increased the number of DCX ${ }^{+}$cells compared with that of the vehicle in Ap $0 a_{1}$ mice $\left({ }^{* * *} p<0.001\right.$, Student's $t$ test; $n=7$ animals per genotype).

al., 2008), and (2) the DG of the hippocampus is associated with depression-related behavior (Sahay and Hen, 2007; Adachi et al., 2008). When we measured phosphorylation of CREB on serine 133 in the hippocampi of Ap oa mice and WT littermates $2 \mathrm{~h}$ after the last injection of octopamine, by immunohistochemistry (IHC) and Western blotting, pCREB immunoreactivity was more intense in the hippocampi of transgenics than in WT controls, especially in the DG granular cells [OD (percentage of control): IHC, WT, $100 \pm 15.45 \%$; Ap oa, $400.41 \pm 111.64 \%$, Student's $t$ test, $p=0.000443$; Western blotting: controls, $100 \pm$ 3.03\%; Ap oa $1,159.07 \pm 17.30 \%$, Student's $t$ test, $p=0.006146$ ] (Fig. $3 a, b)$. The increased level of pCREB reported in the CA1 region after a single octopamine injection (Isiegas et al., 2008) was not apparent after chronic treatment. Acute octopamine injection also noticeably increased pCREB in the DG of the Ap oa $2 \mathrm{~h}$ after a single octopamine injection $\left({ }^{* *} p<0.001\right.$; supplemen- tal Fig. $5 a-c$, available at www.jneurosci.org as supplemental material). Neither acute octopamine treatment per se nor expression of Ap oa ${ }_{1}$ per se alters pCREB activation (supplemental Fig. 5a, available at www.jneurosci.org as supplemental material). Thus,

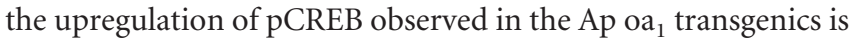
due to conditional activation of Ap oa $\mathrm{b}_{1}$ by the chronic octopamine treatment.

VEGF has been implicated in hippocampal neurogenesis in the rodent brain (Cao et al., 2004; Warner-Schmidt and Duman, 2007) and in antidepression, because it mediates $\mathrm{AD}$ action (Warner-Schmidt and Duman, 2007). Therefore, we further asked whether VEGF expression is upregulated after Ap oa acti- $_{1}$ vation. Chronic Ap oa ${ }_{1}$ activation indeed increased hippocampal VEGF protein (Fig. 3c) when we assessed expression with immunohistochemistry using a specific antibody for VEGF (supplemental Fig. $5 d$, available at www.jneurosci.org as supplemental 
a

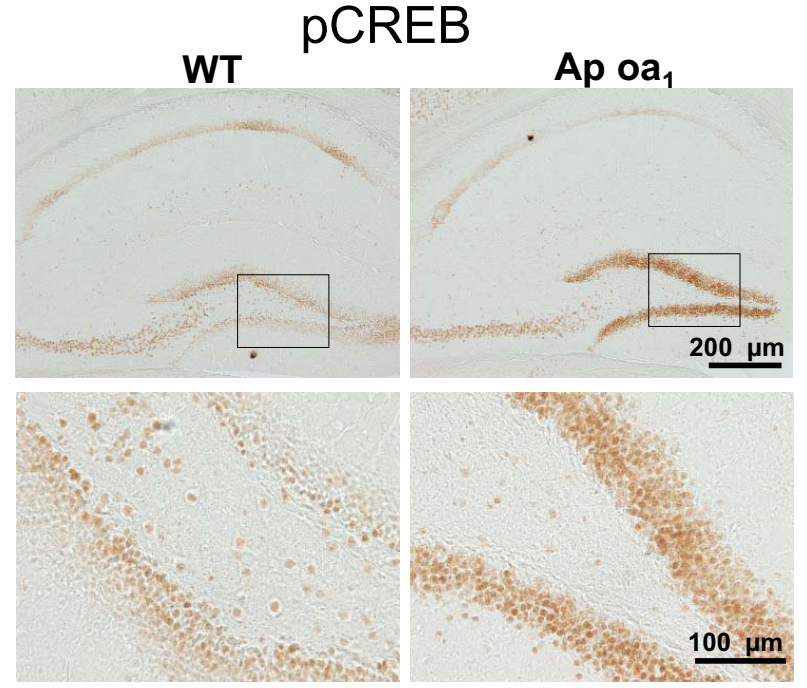

c VEGF
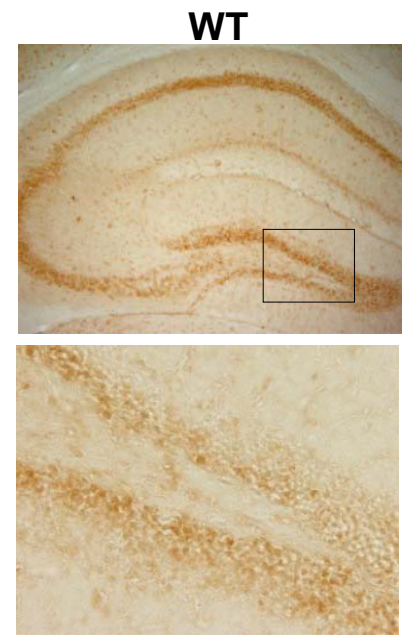

Ap $0 a_{1}$
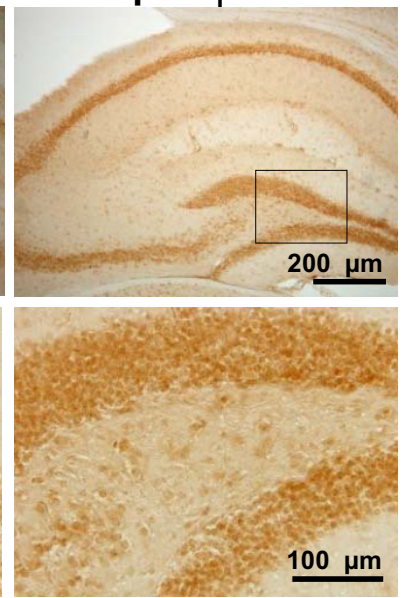

b
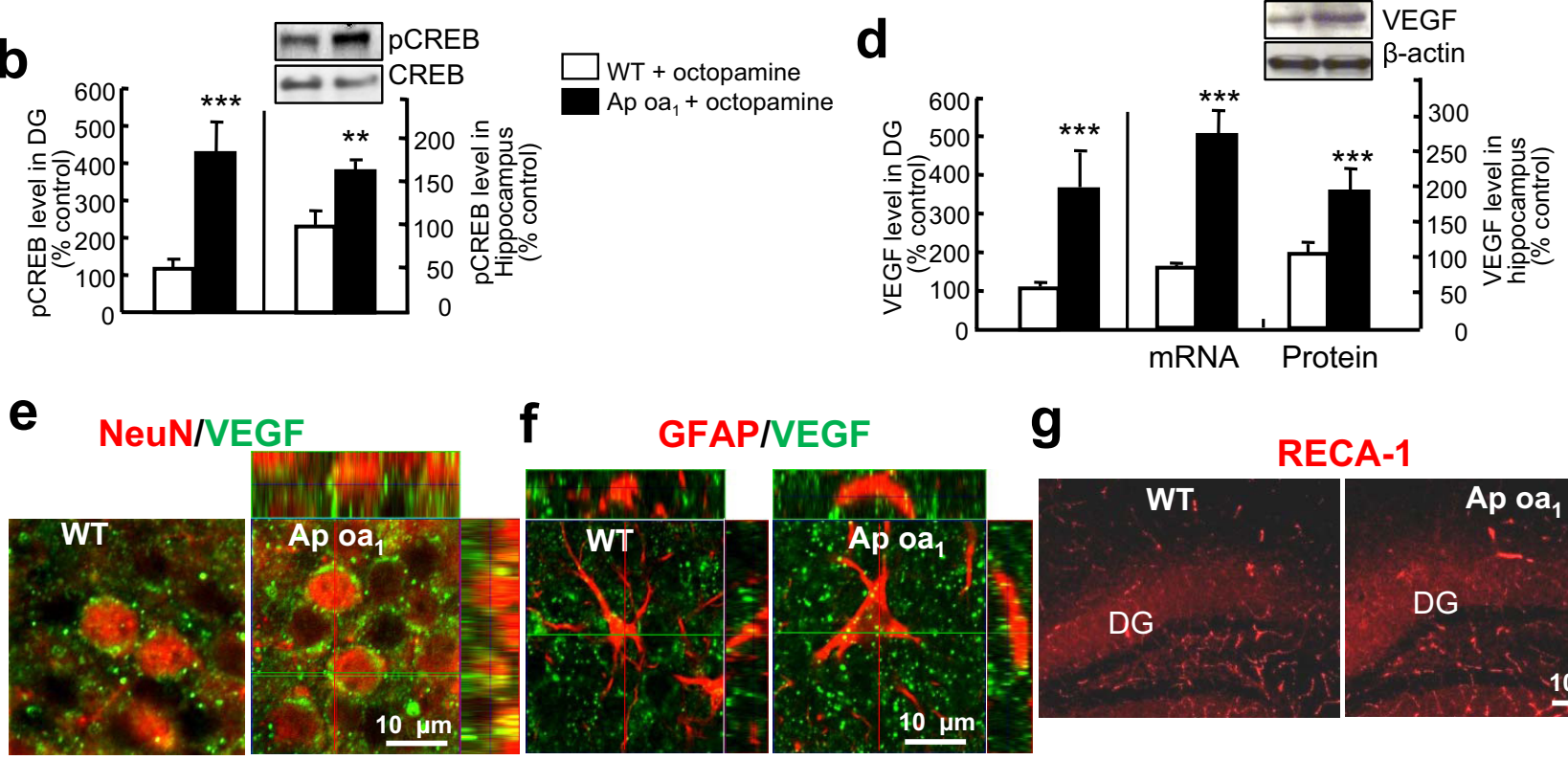

f

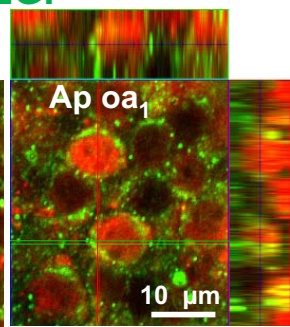

f GFAP/VEGF
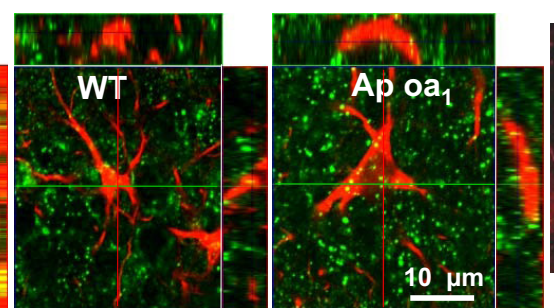

g

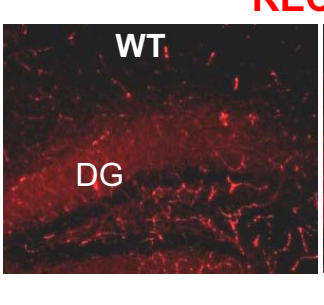

RECA-1

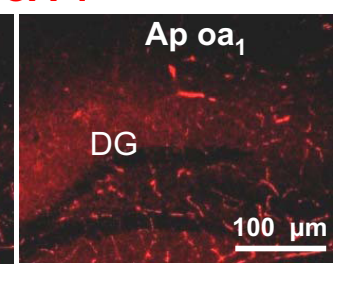

Figure 3. Enhanced CREB phosphorylation and VEGF expression in the hippocampus of Ap oa $\mathrm{a}_{1}$ mice. $\boldsymbol{a}, \mathrm{pCREB}$ levels in the hippocampus $2 \mathrm{~h}$ after the last injection of octopamine (1 $\mathrm{mg} / \mathrm{kg}$ ) treatment for $14 \mathrm{~d}$ in WT and Ap oa ${ }_{1}$ mice. Top: pCREB immunostaining in the whole hippocampus. Bottom: Magnified images of the boxed areas of the DG. $\boldsymbol{b}$, Left: Densitometric analysis of DG granule cells in $\boldsymbol{a}$. Significant effects are seen by genotype (Ap oa ${ }_{1}$ vs WT mice, ${ }^{* * *} p<0.001$, Student's $t$ test; $n=5$ animals per genotype). Data are shown relative to the level in WT mice given octopamine. Right: Quantitative immunoblot analysis of pCREB in whole hippocampi. Top: Representative immunoblots. Bottom: Densitometric analyses of total immunoreactivity. Data are normalized to total CREB in each group, and are shown relative to the level in WT mice given octopamine $\left({ }^{* *} p<0.01\right.$, Student's $t$ test; $n=4$ animals per genotype). $c$, VEGF levels in the hippocampi of Ap oa ${ }_{1}$ mice and WT littermates receiving chronic octopamine treatment. Top: Whole hippocampi. Bottom: Magnified images of the boxed areas of the DG. $\boldsymbol{d}$, Left: Densitometric analyses of DG granule cells in c. Significant effects on genotype are seen after chronic octopamine treatment ( ${ }^{* * *} p<0.001$, Student's $t$ test; $n=5$ animals per genotype). Data are normalized to WT mice. Right: VEGF mRNA and protein expression by quantitative RT-PCR and immunoblot analysis of whole hippocampal homogenates. Significant effects on genotype are seen after chronic octopamine (Ap oa ${ }_{1}$ vs WT, ${ }^{* * *} p<0.001$, Student's $t$ test; $n=4$ animals per genotype). Data are normalized to GAPDH (in mRNA) or $\beta$-actin (in protein) in each group and are shown relative to the level in WT mice. $e_{,}, \boldsymbol{f}$, Colocalization of VEGF (green) with the neuronal marker NeuN (red) or the astrocytic marker GFAP (red) in GCL. VEGF expression was enhanced in neuronal, but not astroglial, cells of the Ap oa 1 mice. The top and right panels show images merged across the $z$ - and $x$-axis, respectively. $\boldsymbol{g}$, The vascular marker RECA-1 (red). The number of RECA ${ }^{+}$vessels is similar to that in the DG, including $\mathrm{GCL}$, molecular layer and hilus from Ap oa $\mathrm{a}_{1}$ and WT mice ( $n=5$ animals per genotype).

material). Levels of VEGF in the granule cell layers (GCL) of the DGs of Ap oa 1 transgenic mice were four-fold higher than in those of their WT littermates [OD (percentage of control): WT, $100 \pm 11.11 \% ;$ Ap oa, $359.23 \pm 80.94 \%$ Student's $t$ test, $p=$ 0.000671] (Fig. 3d). Both VEGF mRNA and protein levels were increased in the hippocampi of Ap oa ${ }_{1}$ mice [mRNA: WT, $100 \pm$ 2.01\%; Ap oa $1,268.20 \pm 25.46 \%$; Student's $t$ test, $p=0.000687$; Western blotting: WT, $100 \pm 5.02 \%$; Ap oa $1,170.20 \pm 27.94 \%$; Student's $t$ test, $p=0.00083422$ ] (Fig. $3 d$ ) similarly to neuronal
VEGF in the DG (Fig. 3e). In contrast, there was no obvious increase in VEGF immunoreactivity in astrocytes, visualized with glial fibrillary acidic protein (GFAP), in the DG of Ap oa mice (Fig. $3 f$ ). These results indicate that the CAMP-induced increase of VEGF occurs mainly in neurons. Since VEGF stimulates angiogenesis (Cao et al., 2004), we also tested for vascular changes in the Ap oa ${ }_{1}$ mice by observing a vascular marker, rat endothelial cell antigen-1 (RECA) (Cao et al., 2004) by immunohistochemistry, but the number of RECA ${ }^{+}$endothelial cells was unchanged 

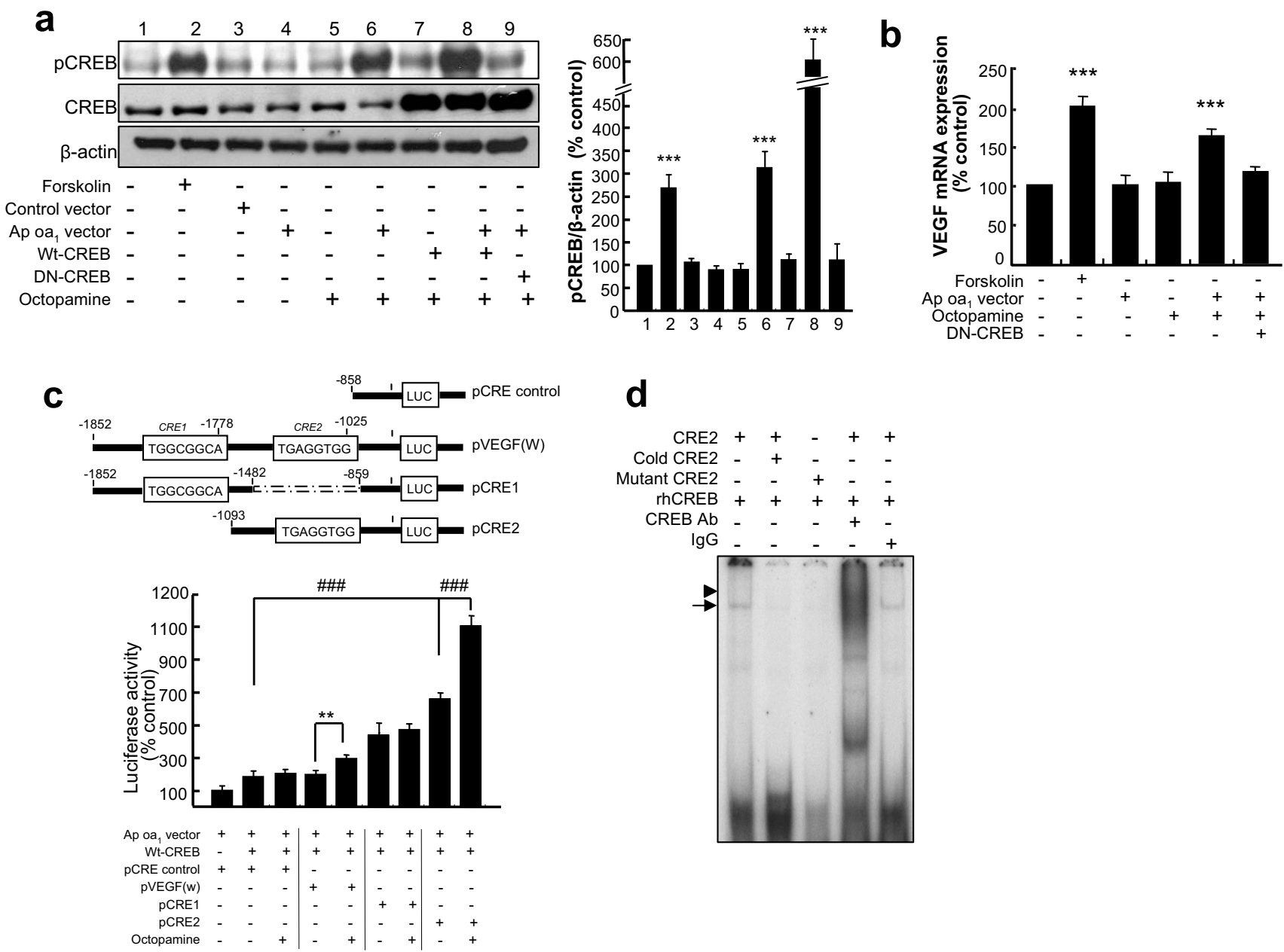

Figure 4. VEGF expression by Ap oa activation. $\boldsymbol{a}$, pCREB was induced by octopamine and $A p$ o $\mathrm{a}_{1}$ in the HEK293 in vitro model system. Left: Representative immunoblots of $p$ CREB, total CREB and $\beta$-actin: $\mathrm{pCREB}$ was induced only in the presence of both Ap $0 \mathrm{a}_{1}$ and octopamine treatment. Right: Densitometric analyses of three independent experiments. Forskolin alone (*** $p<0.001 \mathrm{vs}$ control, Student'st test; $n=4)$ or transfection of $\mathrm{Ap} \mathrm{oa}_{1}$ and octopamine treatment $\left({ }^{* * *} p<0.001\right.$, Student's $t$ test) increased the level of pCREB. Cotransfection with Ap oa and CREB plasmids gave the strongest CREB activation on octopamine treatment $\left({ }^{* * *} p<0.001\right.$, Student's $t$ test). pCREB levels were normalized to the amount of $\beta$-actin, and are shown relative to expression in nontransfected control cells. $\boldsymbol{b}$, Human VEGF165 mRNA induction. Ap oa 1 was transfected into HEK293 cells, and human VEGF165 mRNA was measured by quantitative RT-PCR. Forskolin (10 $\mu \mathrm{m}$ ) added to nontransfected cells for $6 \mathrm{~h}$ demonstrates the cAMP inducibility of VEGF $\left({ }^{* * *} p<0.001\right.$ vs control, Student's ttest; $\left.n=4\right)$. 0ctopamine $(1 \mu \mathrm{m} ; 6 \mathrm{~h}$ treatment) increased VEGF mRNA (*** $p<$ 0.001 vs control, Student's $t$ test). c, VEGF promoter assay. Top: VEGF promoter-reporter constructs used in the reporter assays. Bottom: CRE2 for the induction of VEGF promoter by octopamine. HEK293 cells were transiently transfected with VEGF promoter plasmids, Ap oa ${ }_{1}$ and CREB expression plasmids and treated with octopamine. pVEGF(W) showed an increase in VEGF promoter activity in the presence of octopamine ${ }^{* *} p<0.01$ vs octopamine nontreated, Student's $t$ test; $n=7$ ), and so was $p C R E 2$ ( ${ }^{\# \#} p<0.001$ vs control vector; ${ }^{\# \# \#} p<0.001$ vs octopamine nontreated, Student's $t$ test). pCRE1 did not increase promoter activity in response to octopamine treatment ( $p>0.05$ vs no octopamine). $\boldsymbol{d}$, EMSA. The presence of rhCREB in the VEGF (RE2 binding complex was demonstrated by gel-supershift analysis (arrow). Incubation with cold CRE2 or mutant CRE2 decreased the CRE2 binding. Preincubation of rhCREB with anti-CREB resulted in the formation of a supershifted CRE2 band (arrowhead). Representative image from five independent experiments.

$(\mathrm{WT}, 16.85 \pm 0.83$ vs Ap oa $1,15.52 \pm 1.82$, Student's $t$ test, $p=$ 0.28 ) (Fig. $3 g$ ). Acute octopamine treatment did not increase

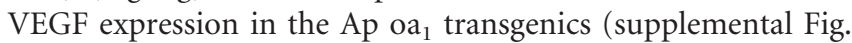
$5 e-g$, available at www.jneurosci.org as supplemental material), suggesting that the increased VEGF expression may represent a neuroadaptive response to chronic Ap oa $\mathrm{o}_{1}$ activation.

We also measured expression of BDNF, a well known CREB target gene (Gass and Riva, 2007), in the hippocampus $24 \mathrm{~h}$ after chronic injection of octopamine, and observed significant increases of BDNF mRNA and protein in Ap oa ${ }_{1}$ mice receiving chronic, but not acute, octopamine treatment (supplemental Fig. 6, available at www.jneurosci.org as supplemental material).

\section{CREB activation causes VEGF increases after Ap $\mathrm{oa}_{1}$ activation}

To test whether VEGF expression is directly affected by CREB activation, we first asked whether Ap oa ${ }_{1}$ activation leads to CREB activation using HEK293 cells, since octopamine elicits a transient increase of cAMP on binding to $\mathrm{G}_{\mathrm{s}}$-coupled Ap oa ${ }_{1}$ receptors expressed in HEK293 cells (Chang et al., 2000). As shown in Figure 4a, in cells cotransfected with Ap $\mathrm{oa}_{1}$ and CREB expression plasmids,

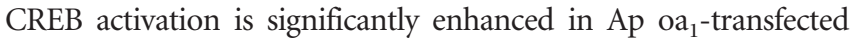
HEK293 cells $30 \mathrm{~min}$ after octopamine $(1 \mu \mathrm{M})$ treatment $(592.00 \pm$ $45.76 \%$ vs nontransfected control, Student's $t$ test, $p=0.00000318$ ). This level was two-fold higher than that observed in cells transfected only with Ap oa ${ }_{1}$ plasmid and treated with octopamine $(311 \pm$ $35.9 \%)$, or in untransfected cells treated with forskolin $(257.13 \pm$ $34.70 \%$ ) (Fig. $4 a$ ). However, CREB activation was unchanged in cells cotransfected with a dominant negative (DN)-CREB (mutated the Ser to Ala in amino acid position 133) (Jeon et al., 2007) together with the Ap oa ${ }_{1}$ plasmids (114.45 $\pm 39.43 \%$ vs nontransfected control, Student's $t$ test, $p=0.055$ ) (Fig. $4 a$ ). In the absence of Ap oa ${ }_{1}$, octopamine treatment had no effect on CREB activation even when the total CREB was increased by overexpression ( $109.31 \pm 9.22 \%$ vs 
nontransfected control, Student's $t$ test, $p=0.29$ ) (Fig. 4a). Together, these results demonstrate that CREB can be efficiently activated by activating Ap oa . $_{\text {. }}$

As shown in Figure $4 b$, when Ap oa ${ }_{1}$ was overexpressed, octopamine significantly increased VEGF mRNA levels in the HEK293 cells $(161.66 \pm 6.95 \%$ vs nontransfected control, Student's $t$ test, $p=0.0001115)$. This effect was blocked by coexpression of DN-CREB, demonstrating that CREB is responsible for VEGF expression (103.25 $\pm 11.63 \%$ vs nontransfected control, Student's $t$ test, $p=0.38)$. Forskolin also increased VEGF mRNA twofold (193.90 $\pm 13.76 \%$ vs nontransfected control, Student's $t$ test, $p=0.000067$ ) (Fig. $4 b$ ).

We next tested to see whether CREB can directly activate the VEGF promoter. The mouse VEGF-A promoter (Accession No. U41383) has a putative CREB binding site at 2000-base pairs (from the base pair +1 to base pair -1852 ) of the promoter region containing two putative CRE sites differing by $2-3 \mathrm{nt}$ from the consensus sequence $\left(5^{\prime}-\right.$ TGACGTCA-3') (Fig. $\left.4 c\right)$. When HEK293 cells transfected with a mouse VEGF promoterluciferase reporter construct together with a wild-type CREB expression construct (Fig. 4c) were treated with octopamine, luciferase activity increased $\sim 1.5$-fold $(197.94 \pm 14.06 \%$ in the absence of octopamine vs $293.66 \pm 23.11 \%$ in the presence of octopamine, Student's $t$ test, $p=0.001939$ ), confirming the presence of Ap oa 1 responsive sites within the VEGF promoter. When we introduced deletion mutants pCRE1 and pCRE2 containing only CRE1 (5'-TGGCGGCA-3' between -1785 and -1778 ) or only CRE2 (5'-TGAGGTGG-3' between -1032 and - 1025), respectively (Fig. 4c), octopamine induced the promoter activity of plasmid pCRE2 $\sim 2$-fold $(657.95 \pm 35.68 \%$ in the absence of octopamine vs $1102.41 \pm 44.08 \%$ in the presence of octopamine, Student's $t$ test, $p=0.0001962)$ whereas it had no effect on pCRE1 activity $(436.06 \pm 19.05 \%$ in the absence of octopamine vs $466.66 \pm 21.02 \%$ in the presence of octopamine, Student's $t$ test, $p=0.27$ ). The activity of pCRE2 under Ap oa ${ }_{1}$ activation cannot be due to the binding of CREB to a hypoxia response element (HRE) because the HRE site ( 5 ' TACGTGGG 3' between -1555 and -1548) is not present in pCRE2. These results demonstrate that Ap $\mathrm{oa}_{1}$-mediated elevation of cAMP activates CREB, and this leads to VEGF transcription.

We then performed gel-supershift experiments to demonstrate the presence of CREB in CRE2 binding complexes (Fig. 4d). Incubation of CREB with a CRE2 probe yielded a prominent CRE band and this was eliminated by excess unlabeled CRE2 oligonucleotide and substantially reduced when we introduced a mutated CRE (differing from CRE2 by two base pairs). Furthermore, the CREB antibody disrupted a faster migrating CRE binding complex, demonstrating that it was active and specific.

To detect CREB binding to the VEGF-A promoter, we performed ChIP assays with CREB antibody on hippocampal extracts of Ap oa ${ }_{1}$ mice $2 \mathrm{~h}$ after the octopamine treatment. As expected, the amount of CREB associated with CRE2 was increased by chronic octopamine treatment (WT, $100 \pm 3.11 \%$ vs Ap oa, $577.29 \pm 28.98 \%$, Student's $t$ test, $p=0.0001834 ; n=5$ animals per group).

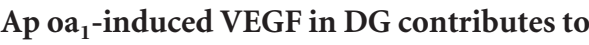 antidepressant-like behavior}

Since Ap oa ${ }_{1}$ activation induced VEGF promoter activity and antidepressive-like behavior in Ap oa ${ }_{1}$ mice, we speculated that neuronal VEGF induced by Ap oa ${ }_{1}$ activation, but not constitutively expressed, contributed to the enhanced antidepressant-like behavior in the Ap oa ${ }_{1}$ mice. To test this notion, we knocked down hippocampal VEGF by bilateral administration of a lentivirus expressing small hairpin RNAs (shRNAs) targeted against mouse VEGF (lenti-shVEGF) into DG granular cells (Fig. 5). Indeed, the lenti-shVEGF treatment promptly repressed VEGF mRNA expression in hippocampal neurons in vitro and this repressive effect was evident with two different lentiviral constructs (Fig. 5a). We therefore injected a mixture of the two types of lenti-shVEGF (50:50) or lenti-EGFP, a control vector expressing EGFP, bilaterally into the DG 2 weeks before octopamine and BrdU injections (Fig. 5b). This resulted in widespread gene expression specifically in DG granule cells weeks after the injection, as shown by the EGFP fluorescence in mice injected with lentiEGFP (Fig. 5c). Immunohistochemical analysis revealed that lenti-shVEGF markedly reduced VEGF protein levels in the DGs of $A p a_{1}$ mice that received octopamine [OD (percentage of lenti-EGFP controls): Ap oa ${ }_{1}$ treated with lenti-EGFP, $215.33 \pm$ $25.56 \%$ versus Ap oa ${ }_{1}$ treated with lenti-shVEGF, $113.80 \pm$ 29.31\%, two-way ANOVA, Tukey's multiple comparison, $p=$ 0.0082] (Fig. 5d,e). However, no effects of lenti-shVEGF were detectable in WT littermates (lenti-EGFP, $100 \pm 3.41 \%$ vs lentishVEGF, $101.69 \pm 21.08 \%$; two-way ANOVA, Tukey's multiple comparison, $p=0.41$ ). Lenti-shVEGF did not reduce the increase of pCREB occurring in response to octopamine in lentiEGFP injected Ap oa ${ }_{1}$ mice (Fig. $5 d$ ), consistent with the idea that VEGF is a downstream effector of CREB. The levels of BDNF mRNA and protein were not affected by lenti-shVEGF in the DGs of Ap oa mice (supplemental Fig. 7, available at www.jneurosci.org as supplemental material). Lenti-shVEGF also reduced VEGF mRNA expres-

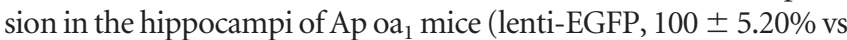
lenti-shVEGF, $90.16 \pm 4.80 \%$, Student's $t$ test, $p=0.002745$ ) (Fig. $5 e$ ), and neuronal VEGF also decreased (Fig. $5 f$ ). To assess whether lenti-shVEGF has an effect on proliferation of cells in the SGZ, proliferating cells were identified by staining for the endogenous marker, Ki67. The number of $\mathrm{Ki}^{+} 7^{+}$cells in the SGZ was significantly decreased in Ap oa ${ }_{1}$ mice injected with lenti-shVEGF compared with lenti-EGFP (lenti-EGFP, $720 \pm 98$ vs lenti-shVEGF, $372 \pm 85$, Student's $t$ test, $p=0.007326$ ) (supplemental Fig. 8 , available at www.jneurosci.org as supplemental material). Additionally, there was a significant difference in the level of cell survival in the SGZ between Ap oa ${ }_{1}$ mice injected with lenti-EGFP and lentishVEGF as determined by the number of $\mathrm{BrdU}^{+}$cells (lenti-EGFP, $1692 \pm 104$ vs lenti-shVEGF, $1347 \pm 76$, Student's $t$ test, $p=$ 0.011561) (supplemental Fig. 8, available at www.jneurosci.org as supplemental material). The effect of lenti-shVEGF on the number of BrdU was evenly distributed throughout the DG (supplemental Fig. 9, available at www.jneurosci.org as supplemental material), consistent with the EGFP expression delivered by lentivirus. VEGF immunoreactivity in astrocytes was not affected by lenti-shVEGF (data not shown, $n=3$ ).

Depressive status was measured 2 weeks after the last octopamine treatment to investigate whether VEGF knockdown abolishes the long-lasting antidepressive effects of Ap oa ${ }_{1}$ activation. The immobility of control mice in response to octopamine was unaffected by either control virus or lenti-shVEGF (lentiEGFP, $150.90 \pm 27.27 \mathrm{~s}$ vs lenti-shVEGF, $151.12 \pm 7.02 \mathrm{~s}$, twoway ANOVA, Tukey's multiple comparison, $p=0.49$ ) (Fig. $5 g$ ), consistent with the fact that lenti-shVEGF did not significantly alter the basal VEGF protein levels. The Ap oa ${ }_{1}$ mice injected with lenti-EGFP and octopamine showed a decrease in immobility time as expected, whereas those injected with lenti-shVEGF and octopamine resembled WT littermates (lenti-EGFP, $164.91 \pm$ $6.89 \mathrm{~s}$ vs lenti-shVEGF, $114.25 \pm 5.13 \mathrm{~s}$; two-way ANOVA, Tukey's multiple comparison, $p=0.000356)$. These behavioral 
a

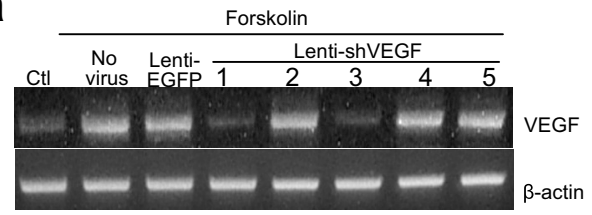

b

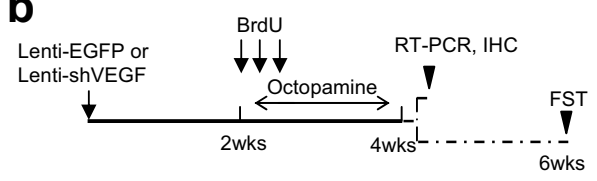

C

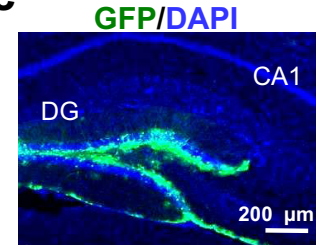

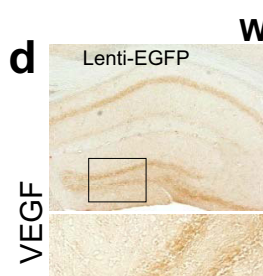

WT

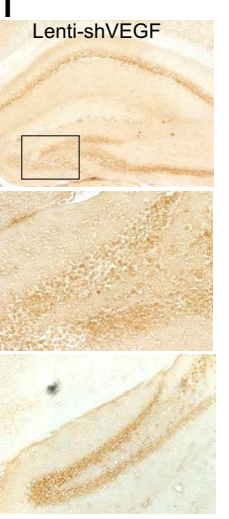

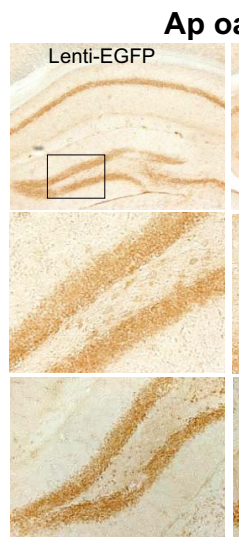

Ap oa

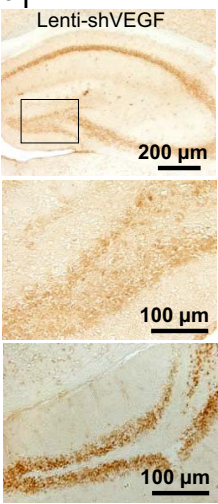

e
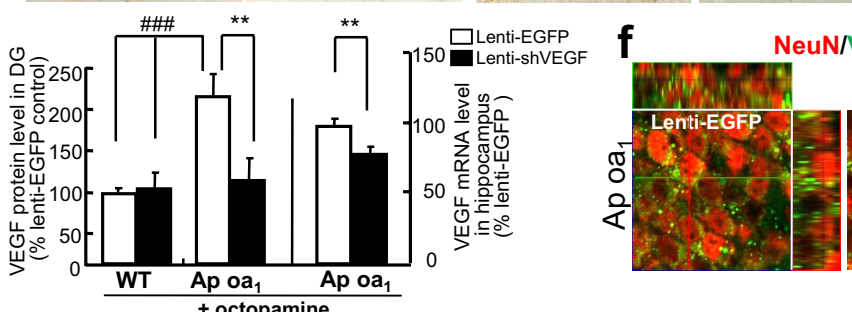

NeuN/VEGF
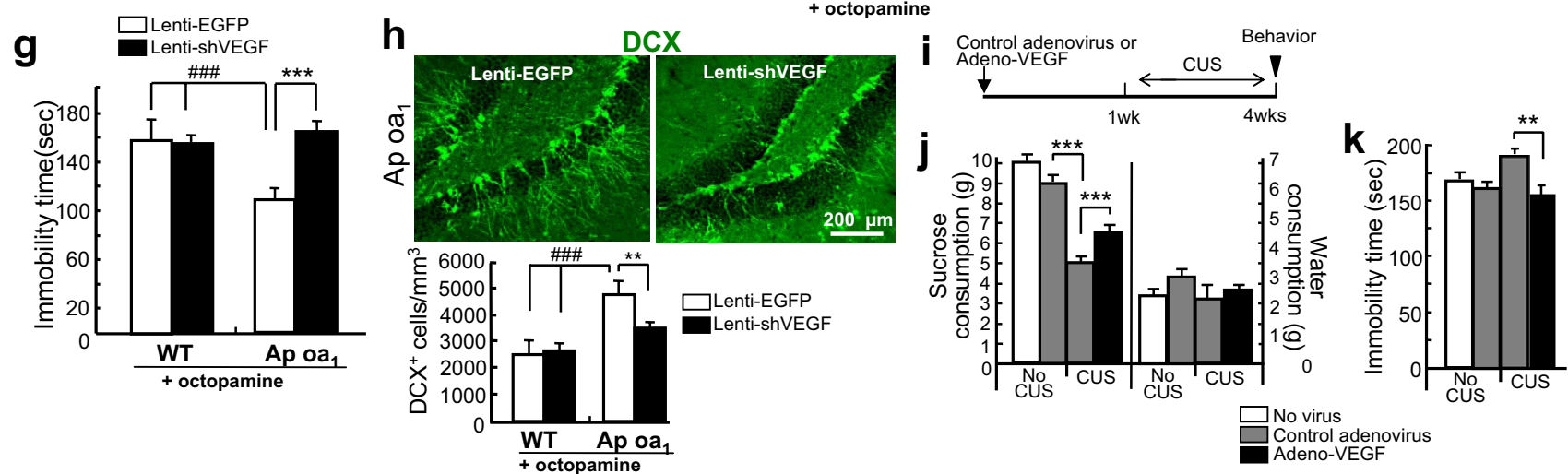

Figure 5. DG specific VEGF expression required for the ability of chronic octopamine to induce antidepressant-like behaviors in Ap oa ${ }_{1}$ transgenic mice. $\boldsymbol{a}$, Knockdown efficiency of lenti-shVEGF by RNA interference (RNAi). Lenti-shVEGF was transfected into mouse primary hippocampal neuronal cells, and mouse VEGF and $\beta$-actin mRNA levels were measured by RT-PCR. Forskolin-induced VEGF mRNA expression was reduced by lenti-shVEGF1 and 3 in vitro. $\boldsymbol{b}$, Experimental design. $\boldsymbol{c}$, Confirmation of the location of viral injection into the DG with lenti-EGFP. EGFP expression was revealed by IHC. $\boldsymbol{d}$, DG-specific knockdown of VEGF and pCREB protein levels. Top: VEGF immunostaining in the whole hippocampus. Middle: Magnified images of DG in the boxed areas. Bottom: pCREB in DG. $\boldsymbol{e}$, Left: Densitometric analyses of VEGF in the DG in $\boldsymbol{d}$. Lenti-shVEGF reduced the VEGF protein level in the DG of Ap oa ${ }_{1}$ transgenic mice $(* * * p<0.001$ vs lenti-EGFP; \#\#\# $p<0.001$ vs WT mice treated with lenti-EGFP or lenti-shVEGF, two-way ANOVA, Tukey's post hoc; $n=10$ animals per group). shVEGF had no significant effects on basal VEGF protein levels ( $p>0.05$, lenti-EGFP vs lenti-shVEGF in WT mice, two-way ANOVA, $n=8$ animals per group). Right: Quantitative RT-PCR. Lenti-shVEGF specifically reduced VEGF mRNA expression in whole hippocampi from Ap oa ${ }_{1}$ mice on octopamine treatment $\left({ }^{* *} p<0.01\right.$ vs lenti-EGFP, Student's test; $n=5$ animals per group). $f$, VEGF $^{+}$and NeuN ${ }^{+}$doubly labeled cells at GCL in lenti-EGFP or lenti-shVEGF injected Ap oa ${ }_{1}$ mice. VEGF expression was reduced in NeuN ${ }^{+}$cells by lenti-shVEGF. $\boldsymbol{g}$, FST. Lenti-shVEGF increased immobility time in Ap oa ${ }_{1}$ transgenic mice ${ }^{* * *} p<0.001$ vs lenti-EGFP; ${ }^{* \# \#} p<0.001$ vs WT mice treated with lenti-EGFP or lenti-shVEGF, two-way ANOVA, Tukey's post hoc; $n=8$ animals per group). Lenti-shVEGF had no significant effects on immobility time in WT mice ( $p>0.05$, lenti-EGFP vs lenti-shVEGF, two-way ANOVA; $n=10$ animals per group). $\boldsymbol{h}, D C^{+}$cells. Top: DCX immunoreactivity. Bottom: Ap oa mice treated with lenti-EGFP increased in DCX ${ }^{+}$cells more than WT mice did $\left({ }^{\# \#} p<0.001\right.$, two-way ANOVA, Tukey's post hoc; $n=4$ animals per group). Ap oa ${ }_{1}$ mice injected with lenti-shVEGFhad significantly fewer DCX ${ }^{+}$cells than lenti-EGFP-injected Ap oa ${ }_{1}$ mice ${ }^{* *} p<$ 0.01, two-way ANOVA, Tukey's post hoc). $\boldsymbol{i}$, Experimental design for (US. $\boldsymbol{j}$, SCT. Left: Injecting mice with Adeno-VEGF before CUS enhanced consumption of sucrose more than injecting mice with control adenovirus before CUS $\left({ }^{* * *} p<0.001\right.$, two-way ANOVA, Tukey's post hoc; $n=9$ animals per group). (Right) There was no difference in water consumption between groups ( $\left.p>0.05\right)$. $\boldsymbol{k}$, FST. Injecting mice with Adeno-VEGF before CUS reduced immobility time over injecting control mice with control virus and exposing them to CUS $\left({ }^{* *} p<0.01\right.$, two-way ANOVA, Tukey's post hoc; $n=9$ animals per group).

effects of lenti-shVEGF were observed in the absence of other changes in total locomotor activities or anxiety (supplemental Fig. 10, available at www.jneurosci.org as supplemental material). These results demonstrate that the induction of VEGF in the DG of the hippocampi contributes to the antidepressant-like behaviors of the Ap oa ${ }_{1}$ mice.

It has been suggested that the behavioral effects of chronic ADs are mediated, at least in part, by stimulation of neurogenesis in the hippocampus (Malberg et al., 2000; Eisch, 2002; Santarelli

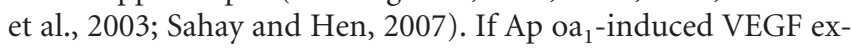
pression in neurons mediates antidepressant-like behavior via neurogenesis, lenti-shVEGF should block the effect on neurogenesis. Indeed, the $A p \mathrm{oa}_{1}$ mice injected with lenti-shVEGF and treated with octopamine for 2 weeks showed a significant decrease in the number of DCX ${ }^{+}$cells compared with $\mathrm{Ap} \mathrm{oa}_{1}$ transgenic mice given lenti-EGFP (lenti-EGFP, $4788.38 \pm 487.63$ vs lenti-shVEGF, $3559.38 \pm 195.54$, two-way ANOVA, Tukey's multiple comparison, $p=0.00415$ ) (Fig. 5h). Lenti-shVEGF did not seem to have an effect on baseline neurogenesis in WT mice (lenti-EGFP, $2596.31 \pm 572.19$ vs lenti-shVEGF, 2657.23 \pm 270.72 , two-way ANOVA, Tukey's multiple comparison, $p=0.33$ ), in line with observations that it does not have substantial effects on basal 
a

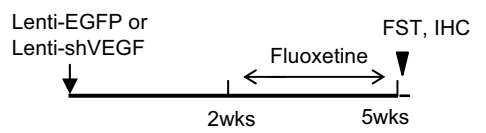

b
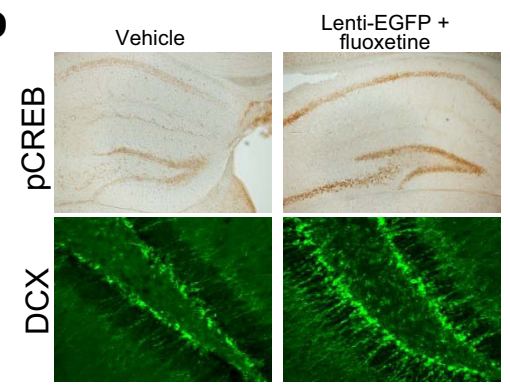

Lenti-shVEGF + fluoxetine
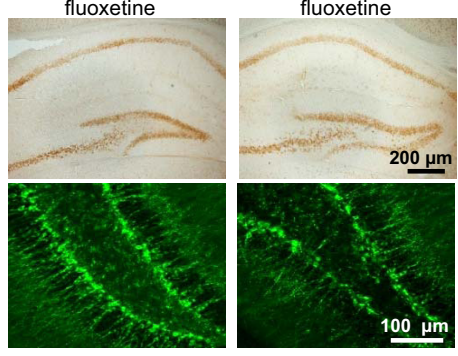

d

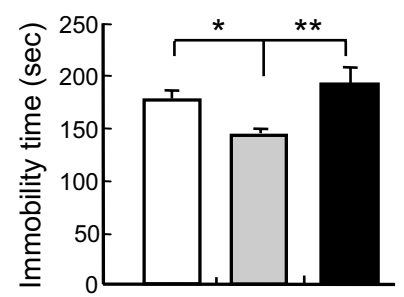

Figure 6. Blockade of fluoxetine-induced antidepressive behavioral effects by RNAi knockdown of VEGF in DG. $\boldsymbol{a}$, Experimental design. Fluoxetine $(10 \mathrm{mg} / \mathrm{kg}$ ) was administered daily for $21 \mathrm{~d}$. $\boldsymbol{b}$, Fluoxetine-induced pCREB and neurogenesis. Top: Fluoxetineinduced pCREB is not reduced by lenti-shVEGF. Bottom: Chronic fluoxetine-treated mice exposed to lenti-shVEGF form fewer $D C X^{+}$cells than those exposed to lenti-EGFP. $c$, The number of DCX ${ }^{+}$cells in the DG in $\boldsymbol{b}$. $\left({ }^{* *} p<0.01\right.$, two-way ANOVA, Tukey's post hoc; $n=7$ animals per group). $\boldsymbol{d}$, FST. Fluoxetine decreases immobility time compared with vehicle treatment $\left({ }^{*} p<0.05\right)$. In mice given fluoxetine and lenti-shVEGF increases immobility time to the level of the vehicle-treated controls $\left({ }^{* *} p<0.01\right.$ vs lenti-EGFP; two-way ANOVA, Tukey's post hoc; $n=10$ animals per group).

VEGF protein levels and immobility time in control mice. These results indicate that the induction of VEGF by $\mathrm{Ap} \mathrm{oa_{1 }}$ in neurons is linked to the stimulation of hippocampal neurogenesis.

To see whether VEGF expression specifically in the DG is responsible for the antidepressive effect in stressful situations, we examined the effect of overexpression of VEGF by adenovirusmediated gene delivery (Adeno-VEGF) specifically to DG on behavior in WT mice exposed to chronic unpredictable stress (CUS) (Willner, 2005; Banasr and Duman, 2008). CUS-exposed animals were tested consecutively for two depressive-like behaviors, SCT and FST, within a $4 \mathrm{~d}$ period (Fig. 5i). CUS decreased the amount of sucrose consumed in control virus-treated animals (non-CUS, $9.0 \pm 0.3$ g vs CUS, $5.0 \pm 0.3$ g; two-way ANOVA, Tukey's multiple comparison, $p=0.000031$ ) (Fig. 5j). Transduction of VEGF before CUS significantly increased the amount of sucrose consumed compared with mice that were not transduced by VEGF (control virus, $5.0 \pm 0.3 \mathrm{~g}$ vs adeno-VEGF, $6.4 \pm 0.3 \mathrm{~g}$, two-way ANOVA, Tukey's multiple comparison, $p=0.000166$ ) (Fig. 5j), indicating that the VEGF overexpressing mice did not fully become anhedonic in stressful conditions. In the FST, immobility time was also reduced in the VEGF overexpressing mice to the control level (control virus, $179.83 \pm 5.82 \mathrm{~s}$ vs adenoVEGF, $153.16 \pm 9.60 \mathrm{~s}$, two-way ANOVA, Tukey's multiple comparison, $p=0.0039$ ) (Fig. $5 k$ ). These results demonstrate that VEGF in the DG is sufficient to confer depression-resistance.

Fluoxetine is a well established AD known to increase VEGF (Warner-Schmidt and Duman, 2007) and neurogenesis (Malberg et al., 2000) in the DG of the hippocampus. We confirmed that fluoxetine increased VEGF and neurogenesis (supplemental Fig. 11, available at www.jneurosci.org as supplemental mate- rial), and therefore tested whether lentishVEGF blocked its antidepressant-like phenotype. Chronic fluoxetine treatment increased the level of pCREB in the hippocampus including the DG and this increase was not affected by previous injection of lenti-shVEGF (Fig. 6b), in line with the results in Ap oa ${ }_{1}$ mice. However, introduction of lenti-shVEGF into the DG before chronic fluoxetine treatment (Fig. 6a) abolished the increase in the neurogenesis (lenti-EGFP and fluoxetine, $7494.44 \pm$ 478.59 vs vehicle, $4896.75 \pm 501.90, p=$ 0.0091; vs lenti-shVEGF and fluoxetine, $3789.42 \pm 363.21, p=0.0073$; two-way ANOVA, $F_{(2,5)}=8.878$; Tukey's post hoc) (Fig. 6b,c), demonstrated by the production of $\mathrm{DCX}^{+}$cells, and prevented the decrease in immobility time in the FST (lenti-EGFP and fluoxetine, $143.4 \pm 2.0 \mathrm{~s}$ vs vehicle, $172.6 \pm 2.9 \mathrm{~s}, p=0.036$; vs lentishVEGF and fluoxetine, $180.8 \pm 10.6 \mathrm{~s}, p=$ 0.009; two-way ANOVA, $F_{(2,11)}=7.373$; Tukey's post hoc) (Fig. 6d). Together, these findings support the idea that $\mathrm{AD}$ effects involve VEGF produced in the DG.

\section{Discussion}

We have shown that activation of heterologously expressed Ap $\mathrm{oa}_{1}$ in forebrain neurons reproduces the behavioral features of an antidepressant-like phenotype and produces long-term neuroadaptation. Both antidepressant activity and increased neurogenesis in mice have been previously linked to VEGF in the endothelial and neuronal pool (Warner-Schmidt and Duman, 2007). By knocking down VEGF specifically in the DG during only a limited period of adulthood around the time of cAMPCREB activation, we were able to demonstrate definitively that inhibiting the production of VEGF in response to the cAMP cascade in the DG abolished the antidepressant-like behavior seen in Ap oa ${ }_{1}$ mice. This finding complements and extends previous observations.

The results of all three antidepressive behavioral tests used indicated that $\mathrm{Ap} \mathrm{oa}$ mice were much more resistant to developing 'depression-like' symptoms than their wild-type congeners. Most notably, even 2 weeks after Ap oa ${ }_{1}$ activation, the Ap oa mice behaved in the FST, NSFT and SCT unlike their WT congeners chronically administered fluoxetine, or Ap oa ${ }_{1}$ mice given acute octopamine. This suggests that chronic Ap oa 1 activation may trigger mechanisms that underlie longer-lasting behavioral effects than those achieved by chronic fluoxetine treatment or acute Ap oa ${ }_{1}$ activation.

Our immunohistochemical data indicated that VEGF immunoreactivity was largely confined to the principal cells of the hippocampus, including the DG granule cells in which strong CREB activation occurred in octopamine-treated Ap $\mathrm{oa}_{1}$ mice. Our finding that DG-specific knockdown of VEGF around the time of cAMP elevation was sufficient to suppress the ligand-induced antidepressive behavior of the Ap oa ${ }_{1}$ mice suggests that VEGF might be required in a specific neuronal population to generate antidepressant-like behaviors. Similarly, knockdown of VEGF 
before fluoxetine treatment abolished both antidepressive and neurogenic effects of fluoxetine.

The idea that neuronal VEGF was responsible for the behavioral effects was further supported by the finding that lenti-shVEGF injected into the DG inhibited both local VEGF levels-primarily in the granular cells - and the antidepressant-like behavior of the

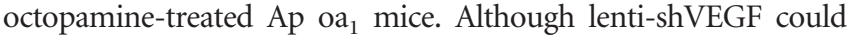
transfect proliferating cells in the SGZ, these cells do not express the Ap $\mathrm{oa}_{1}$ transgene since CaMKII $\alpha$-driven gene expression is restricted to mature glutamatergic neuronal cells, but not adult-born neural progenitor cells (supplemental Fig. 12, available at www. jneurosci.org as supplemental material). Thus, progenitor cells are not likely to contribute to the Ap oa ${ }_{1}$-induced VEGF pool.

The use of our region-specific strategy may improve clinical efficacy when targeting this subregion/pathway to treat mood disorders. Knocking down VEGF in a time-limited and spatially limited manner may have effects that differ from those obtained by the spatially broader functional blockade of VEGF studied earlier (Warner-Schmidt and Duman, 2007). For example, injection of a Flk-1 (VEGF receptor) antagonist into the lateral ventricles (Warner-Schmidt and Duman, 2007) could lead to subtle alterations in other brain functions or signaling and alter neuroplasticity. Thus, the more specific functional downregulation of VEGF in this study may permit a more accurate assessment of the effects of lack of VEGF within the DG granular cells.

There is abundant evidence that behavioral changes in depression and mood disorders in mice involve CREB (Chen et al., 2001; Blendy, 2006; Gass and Riva, 2007) and probably depend on long-lasting changes in the expression of various target genes. We showed that in our system CREB acted via a CRE site in the VEGF promoter. BDNF is also a well known molecule acting downstream of CREB, and plays a role in depression-like behaviors (Ansorge et al., 2006). In studies using similar knockdown approaches using FST as a measure of depression, reduction of BDNF in the DG did not itself cause depression but was found to inhibit the therapeutic efficacy of ADs (Adachi et al., 2008). Forebrain-specific $b d n f^{-/-}$mice display a blunted response to $\mathrm{AD}$ treatment (Monteggia et al., 2007). Since VEGF is also essential for AD action (Warner-Schmidt and Duman, 2007), BDNF and VEGF may act together in mediating the effects of ADs. However, our results show that selectively knocking down VEGF in the DG blocked the octopamine-induced behavioral improvement in $\mathrm{Ap} \mathrm{oa}$ mice even though BDNF was still upregulated. Therefore, BDNF and VEGF signaling may contribute to behavioral effects in different time widows after cAMP elevation. Further studies are ongoing to analyze the differences between the involvement of BDNF and VEGF signaling in antidepressive behavior in response to $\mathrm{CAMP} / \mathrm{CREB}$ activation.

In non-neuronal cells, CREB interacts with HIF- $1 \alpha$ to form a transcription complex which regulates VEGF by binding to an HRE (Wu et al., 2007), and HIF- $1 \alpha$ mRNA increases transiently in the mouse brain in response to short-term environmental enrichment (Rampon et al., 2000). However, we did not detect any increase in HIF- $1 \alpha$ mRNA and protein in octopamine-treated Ap $\mathrm{oa}_{1}$ mice (supplemental Fig. 13, available at www.jneurosci.org as supplemental material); hence, further work is needed to identify possible regulatory partners of CREB.

In addition to or instead of the role of CAMP-CREB signal transduction in neurons, the altered behavior of $\mathrm{Ap} \mathrm{oa}$ mice could reflect the cell type-specific plasticity (i.e., neurogenesis) observed in adulthood. However, CaMKII $\alpha$-driven Ap oa ex- $^{-}$ pression does not extend to adult-born neural progenitor cells in the SGZ (supplemental Fig. 12, available at www.jneurosci.org as supplemental material). The increase of neurogenesis (proliferation and survival) in Ap oa ${ }_{1}$ mice, therefore, is not due to a direct effect of octopamine on neural progenitor cells, but rather involves an action on neighboring mature neurons. This fits well with the role of VEGF in the Ap oa ${ }_{1}$ mice since VEGF is a secreted molecule, and can therefore act as both an autocrine factor on Ap $\mathrm{oa}_{1}$-expressing neuronal cells, and as a paracrine factor by local diffusion to non-neuronal cells, including neural progenitor cells. Hence, we believe that the neuronal expression of VEGF most likely regulates neurogenesis in the SGZ. The octopamine-induced neurogenesis-proliferation and survival of neural progenitor cells in SGZ - was markedly reduced by knocking down VEGF during the period of cAMP elevation, further suggesting that neurogenesis is regulated by VEGF induced primarily in neurons and that VEGF is involved in the proliferation and survival of neural progenitor cells, consistent with previous observations (Jin et al., 2002; Sun et al., 2003; Wada et al., 2006). Previous studies (Cao et al., 2004; Wang et al., 2005) support the idea that neuronal VEGF is locally diffusible and can thus affect neural progenitor cells and blood vessels. However, our data indicate that cAMP-directed neuronal VEGF acts as a neurogenic factor independently of any effects on blood vessels over a period of 2 weeks. Additional studies are warranted to investigate whether the prominent increase of neurogenesis in the octopamineinjected $\mathrm{Ap} \mathrm{oa}$ mice is responsible for the longer-lasting behavioral efficacy in this situation compared with WT mice treated with fluoxetine.

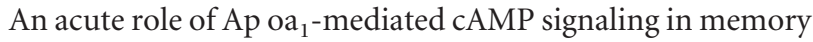
enhancement has been previously reported (Isiegas et al., 2008). Therefore, it is likely that chronic octopamine stimulation of Ap $\mathrm{oa}_{1}$ mice-leading to repeated upregulation of cAMP_causes long-term neuronal adaptation of processes, such as gene expression and neurogenesis, which are known to have a clinical impact in neuropsychiatric disorders. Our findings that neuronal VEGF expression in the adult hippocampus is involved in the shift of emotion in the direction of positive mood and a depressionresistant state, indicate that this heterologous genetic system is a useful tool for clarifying the chronic role of cAMP signaling in mood-related disorders.

\section{References}

Adachi M, Barrot M, Autry AE, Theobald D, Monteggia LM (2008) Selective loss of BDNF in the dentate gyrus attenuates antidepressant efficacy. Biol Psychiatry 63:642-649.

Ansorge MS, Hen R, Gingrich JA (2006) Neurodevelopmental origins of depressive disorders. Curr Opin Pharmacol 7:8-17.

Banasr M, Duman RS (2008) Glial loss in the prefrontal cortex is sufficient to induce depressive-like behaviors. Biol Psychiatry 64:863-870.

Blendy JA (2006) The role of CREB in depression and antidepressant treatment. Biol Psychiatry 59:1144-1150.

Blom JM, Tascedda F, Carra S, Ferraguti C, Barden N, Brunello N (2002) Altered regulation of CREB by chronic antidepressant administration in the brain of transgenic mice with impaired glucocorticoid receptor function. Neuropsychopharmacology 26:605-614.

Cao L, Jiao X, Zuzga DS, Liu Y, Fong DM, Young D, During MJ (2004) VEGF links hippocampal activity with neurogenesis, learning and memory. Nat Genet 36:827-835.

Chang DJ, Li XC, Lee YS, Kim HK, Kim US, Cho NJ, Lo X, Weiss KR, Kandel ER, Kaang BK (2000) Activation of a heterologously expressed octopamine receptor coupled only to adenylyl cyclase produces all the features of presynaptic facilitation in Aplysia sensory neurons. Proc Natl Acad Sci U S A 97:1829-1834.

Chen AC, Shirayama Y, Shin KH, Neve RL, Duman RS (2001) Expression of the cAMP response element binding protein (CREB) in hippocampus produces an antidepressant effect. Biol Psychiatry 49:753-762.

Couillard-Despres S, Winner B, Schaubeck S, Aigner R, Vroemen M, Weidner N, Bogdahn U, Winkler J, Kuhn HG, Aigner L (2005) Doublecortin expression levels in adult brain reflect neurogenesis. Eur J Neurosci 21:1-14. 
Crestani F, Lorez M, Baer K, Essrich C, Benke D, Laurent JP, Belzung C, Fritschy JM, Lüscher B, Mohler H (1999) Decreased GABAA-receptor clustering results in enhanced anxiety and a bias for threat cues. Nat Neurosci 2:833-839.

Dulawa SC, Holick KA, Gundersen B, Hen R (2004) Effects of chronic fluoxetine in animal models of anxiety and depression. Neuropsychopharmacology 29:1321-1330.

Duman RS, Monteggia LM (2006) A neurotrophic model for stress-related mood disorders. Biol Psychiatry 5:1116-1127.

Durden DA, Philips SR (1980) Kinetic measurements of the turnover rates of phenylethylamine and tryptamine in vivo in the rat brain. J Neurochem 34:1725-1732.

Eisch AJ (2002) Adult neurogenesis: implications for psychiatry. Prog Brain Res 138:315-342.

Gass P, Riva MA (2007) CREB, neurogenesis and depression. Bioessays 29:957-961.

Griebel G, Simiand J, Steinberg R, Jung M, Gully D, Roger P, Geslin M, Scatton B, Maffrand JP, Soubrié P (2002) 4-(2-Chloro-4-methoxy-5methylphenyl)-N-[(1S)-2-cyclopropyl-1-(3-fluoro-4-methylphenyl) ethyl]5-methyl-N-(2-propynyl)-1,3-thiazol-2-amine hydrochloride (SSR125543A), a potent and selective corticotrophin-releasing factor(1) receptor antagonist. II. Characterization in rodent models of stressrelated disorders. J Pharmacol Exp Ther 301:333-345.

Gur TL, Conti AC, Holden J, Bechtholt AJ, Hill TE, Lucki I, Malberg JE, Blendy JA (2007) cAMP response element-binding protein deficiency allows for increased neurogenesis and a rapid onset of antidepressant response. J Neurosci 27:7860-7868.

Impey S, McCorkle SR, Cha-Molstad H, Dwyer JM, Yochum GS, Boss JM, McWeeney S, Dunn JJ, Mandel G, Goodman RH (2004) Defining the CREB regulon: a genome-wide analysis of transcription factor regulatory regions. Cell 119:1041-1054.

Isiegas C, McDonough C, Huang T, Havekes R, Fabian S, Wu LJ, Xu H, Zhao MG, Kim JI, Lee YS, Lee HR, Ko HG, Lee N, Choi SL, Lee JS, Son H, Zhuo M, Kaang BK, Abel T (2008) A novel conditional genetic system reveals that increasing neuronal cAMP enhances memory and retrieval. J Neurosci 28:6220-6230.

Jeon SH, Chae BC, Kim HA, Seo GY, Seo DW, Chun GT, Yie SW, Eom SH, Kim PH (2007) The PKA/CREB pathway is closely involved in VEGF expression in mouse macrophages. Mol Cells 23:23-29.

Jin K, Zhu Y, Sun Y, Mao XO, Xie L, Greenberg DA (2002) Vascular endothelial growth factor (VEGF) stimulates neurogenesis in vitro and in vivo. Proc Natl Acad Sci U S A 99:11946-11950.

Kim BW, Choi M, Kim YS, Park H, Lee HR, Yun CO, Kim EJ, Choi JS, Kim S, Rhim H, Kaang BK, Son H (2008) Vascular endothelial growth factor (VEGF) signaling regulates hippocampal neurons by elevation of intracellular calcium and activation of calcium/calmodulin protein kinase II and mammalian target of rapamycin. Cell Signal 20:714-725.

Kim JS, Chang MY, Yu IT, Kim JH, Lee SH, Lee YS, Son H (2004) Lithium selectively increases neuronal differentiation of hippocampal neural progenitor cells both in vitro and in vivo. J Neurochem 89:324-336.

Lucki I (1997) The forced swimming test as a model for core and component behavioral effects of antidepressant drugs. Behav Pharmacol 8:523-532.

Malberg JE, Eisch AJ, Nestler EJ, Duman RS (2000) Chronic antidepressant treatment increases neurogenesis in adult rat hippocampus. J Neurosci 20:9104-9110.

Monteggia LM, Luikart B, Barrot M, Theobold D, Malkovska I, Nef S, Parada LF, Nestler EJ (2007) Brain-derived neurotrophic factor conditional knockouts show gender differences in depression-related behaviors. Biol Psychiatry 61:187-197.

Nakagawa S, Kim JE, Lee R, Malberg JE, Chen J, Steffen C, Zhang YJ, Nestler EJ, Duman RS (2002a) Regulation of neurogenesis in adult mouse hippocampus by cAMP and the cAMP response element-binding protein. J Neurosci 22:3673-3682.

Nakagawa S, Kim JE, Lee R, Chen J, Fujioka T, Malberg J, Tsuji S, Duman RS (2002b) Localization of phosphorylated cAMP response elementbinding protein in immature neurons of adult hippocampus. J Neurosci 22:9868-9876.

Nestler EJ, Barrot M, DiLeone RJ, Eisch AJ, Gold SJ, Monteggia LM (2002) Neurobiology of depression. Neuron 34:13-25.

Nibuya M, Morinobu S, Duman RS (1995) Regulation of BDNF and trkB mRNA in rat brain by chronic electroconvulsive seizure and antidepressant drug treatments. J Neurosci 15:7539-7547.
Nibuya M, Nestler EJ, Duman RS (1996) Chronic antidepressant administration increases the expression of cAMP response element binding protein (CREB) in rat hippocampus. J Neurosci 16:2365-2372.

Paterson IA, Juorio AV, Boulton AA (1990) 2-Phenylethylamine: a modulator of catecholamine transmission in the mammalian central nervous system. J Neurochem 55:1827-1837.

Porsolt RD, Le Pichon M, Jalfre M (1977) Depression: a new animal model sensitive to antidepressant treatments. Nature 266:730-732.

Rampon C, Jiang CH, Dong H, Tang YP, Lockhart DJ, Schultz PG, Tsien JZ, Hu Y (2000) Effects of environmental enrichment on gene expression in the brain. Proc Natl Acad Sci U S A 97:12880-12884.

Rubinson DA, Dillon CP, Kwiatkowski AV, Sievers C, Yang L, Kopinja J, Rooney DL, Zhang M, Ihrig MM, McManus MT, Gertler FB, Scott ML, Van Parijs L (2003) A lentivirus-based system to functionally silence genes in primary mammalian cells, stem cells and transgenic mice by RNA interference. Nat Genet 33:401-406.

Sahay A, Hen R (2007) Adult hippocampal neurogenesis in depression. Nat Neurosci 10:1110-1115.

Sairanen M, Lucas G, Ernfors P, Castrén M, Castrén E (2005) Brain-derived neurotrophic factor and antidepressant drugs have different but coordinated effects on neuronal turnover, proliferation, and survival in the adult dentate gyrus. J Neurosci 25:1089-1094.

Santarelli L, Gobbi G, Debs PC, Sibille ET, Blier P, Hen R, Heath MJ (2001) Genetic and pharmacological disruption of neurokinin 1 receptor function decreases anxiety-related behaviors and increases serotonergic function. Proc Natl Acad Sci U S A 98:1912-1917.

Santarelli L, Saxe M, Gross C, Surget A, Battaglia F, Dulawa S, Weisstaub N, Lee J, Duman R, Arancio O, Belzung C, Hen R (2003) Requirement of hippocampal neurogenesis for the behavioral effects of antidepressants. Science 301:805-809.

Shima DT, Gougos A, Miller JW, Tolentino M, Robinson G, Adamis AP, D'Amore PA (1996) Cloning and mRNA expression of vascular endothelial growth factor in ischemic retinas of Macaca fascicularis. Invest Ophthalmol Vis Sci 37:1334-1340.

Son H, Yu IT, Hwang SJ, Kim JS, Lee SH, Lee YS, Kaang BK (2003) Lithium enhances long-term potentiation independently of hippocampal neurogenesis in the rat dentate gyrus. J Neurochem 85:872-881.

Sun Y, Jin K, Xie L, Childs J, Mao XO, Logvinova A, Greenberg DA (2003) VEGF-induced neuroprotection, neurogenesis, and angiogenesis after focal cerebral ischemia. J Clin Invest 111:1843-1851.

Thome J, Sakai N, Shin K, Steffen C, Zhang YJ, Impey S, Storm D, Duman RS (2000) cAMP response element-mediated gene transcription is upregulated by chronic antidepressant treatment. J Neurosci 20:4030-4036.

Tiraboschi E, Tardito D, Kasahara J, Moraschi S, Pruneri P, Gennarelli M, Racagni G, Popoli M (2004) Selective phosphorylation of nuclear CREB by fluoxetine is linked to activation of CaM kinase IV and MAP kinase cascades. Neuropsychopharmacology 29:1831-1840.

Wada T, Haigh JJ, Ema M, Hitoshi S, Chaddah R, Rossant J, Nagy A, van der Kooy D (2006) Vascular endothelial growth factor directly inhibits primitive neural stem cell survival but promotes definitive neural stem cell survival. J Neurosci 26:6803-6812.

Wang Y, Kilic E, Kilic U, Weber B, Bassetti CL, Marti HH, Hermann DM (2005) VEGF overexpression induces post-ischaemic neuroprotection, but facilitates haemodynamic steal phenomena. Brain 128:52-63.

Warner-Schmidt JL, Duman RS (2007) VEGF is an essential mediator of the neurogenic and behavioral actions of antidepressants. Proc Natl Acad Sci U S A 104:4647-4652.

Warner-Schmidt JL, Duman RS (2008) VEGF as a potential target for the therapeutic intervention in depression. Curr Opin Pharmacol 8:14-19.

Wells J, Farnham PJ (2002) Characterizing transcription factor binding sites using formaldehyde crosslinking and immunoprecipitation. Methods 26:48-56.

Willner P (2005) Chronic mild stress (CMS) revisited: consistency and behavioural-neurobiological concordance in the effects of CMS. Neuropsychobiology 52:90-110.

Wu D, Zhau HE, Huang WC, Iqbal S, Habib FK, Sartor O, Cvitanovic L, Marshall FF, Xu Z, Chung LW (2007) cAMP-responsive element-binding protein regulates vascular endothelial growth factor expression: implication in human prostate cancer bone metastasis. Oncogene 26:5070-5077.

Wu LJ, Steenland HW, Kim SS, Isiegas C, Abel T, Kaang BK, Zhuo M (2008) Enhancement of presynaptic glutamate release and persistent inflammatory pain by increasing neuronal cAMP in the anterior cingulate cortex. Mol Pain 4:40. 